\title{
RMetS
}

\section{The Convective and Orographically-induced Precipitation Study (COPS): the scientific strategy, the field phase, and research highlights}

Volker Wulfmeyer, ${ }^{\mathrm{a} \star}$ Andreas Behrendt, ${ }^{\mathrm{a}}$ Christoph Kottmeier, ${ }^{\mathrm{b}}$ Ulrich Corsmeier, ${ }^{\mathrm{b}}$ Christian Barthlott, ${ }^{\mathrm{b}}$ George C. Craig, ${ }^{\mathrm{c}}$ Martin Hagen, ${ }^{\mathrm{c}}$ Dietrich Althausen, ${ }^{\mathrm{d}}$ Fumiko Aoshima, ${ }^{\mathrm{a}}$ Marco Arpagaus, ${ }^{\mathrm{e}}$ Hans-Stefan Bauer, ${ }^{\mathrm{a}}$ Lindsay Bennett, ${ }^{\mathrm{f}}$ Alan Blyth, ${ }^{\mathrm{f}}$ Christine Brandau, ${ }^{\mathrm{g}}$ Cédric Champollion, ${ }^{\mathrm{h}}$ Susanne Crewell, ${ }^{\mathrm{i}}$ Galina Dick, ${ }^{\mathrm{j}}$ Paolo Di Girolamo, ${ }^{\mathrm{k}}$ Manfred Dorninger, ${ }^{\mathrm{l}}$ Yann Dufournet, ${ }^{\mathrm{g}}$ Rafael Eigenmann, ${ }^{\mathrm{m}}$ Ronny Engelmann, ${ }^{\mathrm{d}}$ Cyrille Flamant, ${ }^{\mathrm{n}}$ Thomas Foken, ${ }^{\mathrm{m}}$ Theresa Gorgas, ${ }^{1}$ Matthias Grzeschik, ${ }^{\mathrm{a}, \mathrm{cc}}$ Jan Handwerker, ${ }^{\mathrm{b}}$ Christian Hauck, ${ }^{\mathrm{o}}$ Hartmut Höller, ${ }^{\mathrm{c}}$ Wolfgang Junkermann, ${ }^{\mathrm{p}}$ Norbert Kalthoff, ${ }^{\mathrm{b}}$ Christoph Kiemle, ${ }^{\mathrm{c}}$ Stefan Klink, ${ }^{\mathrm{q}}$ Marianne König, ${ }^{\mathrm{r}}$ Liane Krauss, ${ }^{\mathrm{b}}$ Charles N. Long, ${ }^{\mathrm{s}}$ Fabio Madonna, ${ }^{\mathrm{t}}$ Stephen Mobbs, ${ }^{\mathrm{f}}$ Bruno Neininger, ${ }^{\mathrm{u}}$ Sandip Pal, ${ }^{\mathrm{a}}$ Gerhard Peters, ${ }^{\mathrm{v}}$ Grégoire Pigeon, ${ }^{\mathrm{w}}$ Evelyne

Richard, ${ }^{\mathrm{x}}$ Mathias W. Rotach, ${ }^{\mathrm{e}, \mathrm{dd}}$ Herman Russchenberg, ${ }^{\mathrm{g}}$ Thomas Schwitalla, ${ }^{\mathrm{a}}$ Victoria Smith, ${ }^{\mathrm{f}}$ Reinhold Steinacker, ${ }^{\mathrm{l}}$ Jörg Trentmann, ${ }^{\mathrm{q}}$ David D. Turner, ${ }^{\mathrm{y}}$ Joel van Baelen, ${ }^{\mathrm{z}}$ Siegfried Vogt, ${ }^{\mathrm{b}}$ Hans Volkert, ${ }^{\mathrm{c}}$ Tammy Weckwerth, ${ }^{\mathrm{a} \dagger}{ }^{\dagger}$ Heini Wernli, ${ }^{\text {bb }}$ Andreas Wieser ${ }^{\mathrm{b}}$ and Martin Wirth ${ }^{\mathrm{c}}$

anstitute of Physics and Meteorology (IPM), University of Hohenheim (UHOH), Stuttgart, Germany

${ }^{\mathrm{b}}$ Institute for Meteorology and Climate Research, Karlsruhe Institute of Technology (KIT), Karlsruhe, Germany

${ }^{c}$ Deutsches Zentrum für Luft- und Raumfahrt (DLR), Institut für Physik der Atmosphäre (IPA), Oberpfaffenhofen, Germany

${ }^{\mathrm{d}}$ Leibniz Institute for Tropospheric Research, Leipzig, Germany

${ }^{\mathrm{e}}$ MeteoSwiss, Zurich, Switzerland

${ }^{\mathrm{f}}$ School of Earth and Environment, University of Leeds, UK

${ }^{\mathrm{g}}$ Delft University of Technology, The Netherlands

${ }^{\mathrm{h}}$ Géosciences Montpellier, CNRS, Université Montpellier II, France

institute for Geophysics and Meteorology, University of Cologne, Germany

${ }^{j}$ Helmholtz Centre Potsdam, GFZ German Research Centre for Geosciences, Germany

${ }^{\mathrm{k}}$ Dipartimento di Ingegneria e Fisica dell'Ambiente (DIFA), Università della Basilicata (UNIBAS), Potenza, Italy

${ }^{1}$ Department of Meteorology and Geophysics, University of Vienna, Austria

${ }^{\mathrm{m}}$ Department of Micrometeorology, University of Bayreuth, Germany

${ }^{\mathrm{n}}$ Laboratoire Atmosphères, Milieux, Observations Spatiales, CNRS/UPMC/UVSQ, Paris, France

${ }^{\circ}$ Department of Geosciences, University of Fribourg, Switzerland

${ }^{\mathrm{p}}$ Karlsruhe Institute of Technology (KIT), IMK-IFU, Garmisch-Partenkirchen, Germany

${ }^{\mathrm{q}}$ Deutscher Wetterdienst (DWD, German Meteorological Service), Offenbach, Germany ${ }^{\mathrm{r}}$ EUMETSAT, Darmstadt, Germany

${ }^{s}$ Pacific Northwest National Laboratory (PNNL), Richland, USA

${ }^{\mathrm{t}}$ Istituto di Metodologie per l'Analisi Ambientale, CNR - IMAA, Potenza, Italy

"METAIR AG, Hausen am Albis, Switzerland

${ }^{\mathrm{v}}$ Institute of Meteorology, University of Hamburg, Germany

${ }^{\mathrm{w}}$ CNRM-GAME, Météo-France-CNRS, Toulouse, France

${ }^{\mathrm{x}}$ Laboratoire d'Aérologie, CNRS and University of Toulouse, Toulouse, France

y Department of Atmospheric and Oceanic Sciences, University of Wisconsin-Madison, USA

${ }^{\mathrm{z}}$ Laboratoire de Météorologie Physique, Université Blaise Pascal, Clermont-Ferrand, France

aa National Center of Atmospheric Research (NCAR), Boulder, CO, USA

${ }^{\mathrm{bb}}$ Institute for Atmospheric and Climate Science, ETH Zurich, Switzerland

${ }^{c c}$ Water - Earth System Science Research Institute, Tübingen, Germany

${ }^{\mathrm{dd}}$ Institute for Meteorology and Geophysics, University of Innsbruck, Austria

${ }^{*}$ Correspondence to: Volker Wulfmeyer, University of Hohenheim, Institute of Physics and Meteorology, Garbenstrasse

30, Stuttgart D-70599, Germany. E-mail: volker.wulfmeyer@uni-hohenheim.de

${ }^{\dagger}$ The contribution of Tammy Weckwerth to this article was prepared as part of her official duties as a US Government employee. 
Within the framework of the international field campaign COPS (Convective and Orographically-induced Precipitation Study), a large suite of state-of-the-art meteorological instrumentation was operated, partially combined for the first time. This includes networks of in situ and remote-sensing systems such as the Global Positioning System as well as a synergy of multi-wavelength passive and active remote-sensing instruments such as advanced radar and lidar systems. The COPS field phase was performed from 01 June to 31 August 2007 in a low-mountain area in southwestern Germany/eastern France covering the Vosges mountains, the Rhine valley and the Black Forest mountains. The collected data set covers the entire evolution of convective precipitation events in complex terrain from their initiation, to their development and mature phase until their decay. Eighteen Intensive Observation Periods with 37 operation days and eight additional Special Observation Periods were performed, providing a comprehensive data set covering different forcing conditions. In this article, an overview of the COPS scientific strategy, the field phase, and its first accomplishments is given. Highlights of the campaign are illustrated with several measurement examples. It is demonstrated that COPS research provides new insight into key processes leading to convection initiation and to the modification of precipitation by orography, in the improvement of quantitative precipitation forecasting by the assimilation of new observations, and in the performance of ensembles of convection-permitting models in complex terrain. Copyright (C) 2011 Royal Meteorological Society

Key Words: convection; aerosol-cloud-precipitation microphysics; data assimilation; land-surface exchange; orography; quantitative precipitation forecasting; thermally induced flow; verification

Received 12 February 2010; Revised 15 November 2010; Accepted 26 November 2010; Published online in Wiley Online Library 11 February 2011

Citation: Wulfmeyer V, Behrendt A, Kottmeier C, Corsmeier U, Barthlott C, Craig GC, Hagen M, Althausen D, Aoshima F, Arpagaus M, Bauer H-S, Bennett L, Blyth A, Brandau C, Champollion C, Crewell S, Dick G, Di Girolamo P, Dorninger M, Dufournet Y, Eigenmann R, Engelmann R, Flamant C, Foken T, Gorgas T, Grzeschik M, Handwerker J, Hauck C, Höller H, Junkermann W, Kalthoff N, Kiemle C, Klink S, König M, Krauss L, Long CN, Madonna F, Mobbs S, Neininger B, Pal S, Peters G, Pigeon G, Richard E, Rotach MW, Russchenberg H, Schwitalla T, Smith V, Steinacker R, Trentmann J, Turner DD, van Baelen J, Vogt S, Volkert H, Weckwerth T, Wernli H, Wieser A, Wirth M. 2011. The Convective and Orographically-induced Precipitation Study (COPS): The scientific strategy, the field phase, and research highlights. Q. J. R. Meteorol. Soc. 137: 3-30. DOI:10.1002/qj.752

\section{Introduction}

In atmospheric sciences, PrQPF is a vital topic and a major challenge at the same time. As high-quality simulations of precipitation and the assessment of their uncertainty are essential for applications on nearly all temporal and spatial scales, PrQPF forms a cornerstone of both weather and climate research.

On short- to medium-range time-scales, relevant applications include hydrological ones, e.g. PrQPF as input for (ensemble) hydrological models, water quality assessment, and transport and conversion of chemical quantities in the soil, as well as agricultural ones for optimising land use and protection of crops from extreme events. On seasonal to decadal time-scales or beyond, high-quality probabilistic simulations of precipitation are essential for the accurate determination of the regional water cycle. Only if the absolute amount and the regional distribution of precipitation (and thus the water content in the soil) are simulated with high accuracy down to the scales

\footnotetext{
${ }^{\ddagger}$ All abbreviations and acronyms are given in the appendix.
}

of land use and orography will climate models yield useful products for decision-makers and end-users.

Accordingly, the coordination of research efforts with respect to PrQPF between the weather and climate communities is a major concern. Among the organizations that have taken up this cause are the WMO and its WWRP, its WCRP, and the IGBP. The overarching vision relating to the simulation of precipitation on all scales is laid out in the 'seamless approach to weather and climate' as elaborated in the WCRP (WMO, 2009a) and WWRP (WMO, 2009b) science plans.

The improvement of PrQPF is a pressing issue because the present performance and uncertainty assessments generally do not satisfy the needs of end users. Particularly, extreme precipitation events provide a considerable challenge: the very events that have the highest impact for society and economy display low prognostic skill. Due to their sporadic occurrence, they are not observed in sufficient detail and their statistics are rather uncertain. Several studies have demonstrated that on short- to medium-range timescales, the QPF skill decreases considerably if precipitation 
thresholds exceed $10 \mathrm{~mm} \mathrm{~h}^{-1}$ (Ament et al., 2010; Bauer et al., 2011). Generally, the QPF skill degrades during summertime (Weckwerth et al., 2004), which is very likely due to the difficulties of mesoscale models to simulate $\mathrm{CI}$ and its organization during strong and heterogeneous surface heating.

Precipitation climatologies and distribution functions simulated by regional climate models reveal significant biases and incorrect frequency distributions (e.g. Feldmann et al., 2008). Model improvements and verification studies are urgently required so that an acceptable QPF performance with respect to the current atmospheric state can be demonstrated before the next step - the climate projection - is taken. Uncertainty analyses should be provided over the entire duration of the projection.

Two key problems have been identified in connection with PrQPF and climate simulations that are particularly critical in orographic terrain. The windward/lee effect leads to an overestimation of precipitation on the windward side and to an underestimation on the lee side of mountains (Kleinn et al., 2005; Schwitalla et al., 2008; Crewell et al., 2008; Feldmann et al., 2008; Chu et al., 2010). Furthermore, phase and amplitude errors in the diurnal cycle of precipitation lead to a simulated onset of precipitation in models which is several hours too early compared to reality (Chaboureau et al., 2004; Guichard et al., 2004; Paulat et al., 2008). Another open question is to what extent the representation of aerosol-cloud-precipitation microphysics, which is crudely parametrized in most of the current NWP and climate models, is responsible for significant errors in precipitation intensity and distribution. This research topic forms a substantial overlapping issue between weather and climate research.

Considerable efforts have been undertaken to advance the PrQPF skill by increasing the grid resolution of forecast systems, both on the global and on the regional scale. Corresponding global models will provide improved boundary conditions to LAMs. Convection-permitting LAMs are of particular interest because they are starting to break an important barrier: the parametrization of deep convection, which has been identified as a major error source in QPF (Schwitalla et al., 2008; Arpagaus et al., 2009), is no longer required with a grid resolution of $\mathrm{O}(1 \mathrm{~km})$. First results demonstrate that the QPF of convection-permitting models is superior to that of LAMs with convection parametrization (Crewell et al., 2008; Ament et al., 2010; Bauer et al., 2011). It is necessary to confirm these results in other regions and to understand the major differences in model performance, particularly the capability of LAMs to simulate the flow over heterogeneous land surfaces and/or land surfaces with complex orography leading to the initiation and organization of convection. Furthermore, it has not yet been decided which grid size is sufficient for simulations of deep convection without parametrization and whether trigger functions for CI are still required. The interaction of turbulence schemes with aerosol-cloud-precipitation microphysics also has to be analyzed with respect to the quality of QPF.

For high-resolution PrQPF in complex terrain, ensembles of LAMs are required. Advanced LAMs on the convectionpermitting scale will provide the basis for the next generation of ensemble forecast systems, which take into account the increasing chaotic nature and nonlinearity of atmospheric processes. Corresponding research is also indispensable to develop an advanced generation of regional climate model ensemble systems. The research efforts required to this end include the probabilistic verification of various atmospheric variables such as humidity, cloud cover, and precipitation, as well as data assimilation methodology and the assimilation of additional and new high-quality observations.

Understanding and reduction of errors related to PrQPF in low-mountain regions during summertime is the key topic of the field campaign COPS (Wulfmeyer et al., 2008; Richard et al., 2009). High-quality, extended, and condensed datasets were produced for research in three areas:

- Understanding of the process chain leading to CI, clouds, and precipitation in dependence on forcing conditions. Reasons for systematic errors in QPF such as the windward-lee effect and errors in diurnal cycles have been addressed, e.g. by detailed observations of CI.

- The development and application of advanced data assimilation systems including the increased use of observational data. For this purpose, datasets were specified with respect to error characteristics and were provided in near-real time.

- The verification of models to characterise their current performance and to identify the most promising improvements, with a special emphasis on convection-permitting models. This was realised by close collaboration and coordination of the research efforts of modellers and instrument PIs.

Since atmospheric processes are interwoven in model systems, the endeavour to close the remaining gaps in our process understanding requires observations of the full process chain from land-surface exchange, to ABL evolution, to the development, organization, and decay of clouds and precipitation.

Field campaigns for studying QPF have a long tradition and it was the vision of COPS design to derive the utmost advantage from previous experience. The MAP was performed in the 1990s in central Europe, inter alia to improve QPF in high-mountain regions like the Alps (Rotunno and Houze, 2007; Richard et al., 2007; Volkert and Gutermann, 2007). The IHOP_2002 (Weckwerth et al., 2004) was performed in the central US in relatively flat terrain but in a region with strong synoptic gradients (e.g. the dryline) for improving the prediction of warmseason rainfall (Weckwerth and Parsons, 2006). The CSIP was an international project to understand where, when and how convective clouds form and develop into showers in the mainly maritime environment of southern England (Browning et al., 2007). In contrast, precipitation in the COPS region covering low-mountain regions in southwestern Germany/eastern France is due to a complex interaction between large-scale instabilities, modification of mesoscale flow by orography, and thermally induced orographic flow. COPS benefitted from previous campaigns in the region such as TRACT in 1992 (Kossmann et al., 1998), VERTIKATOR in 2002 (Barthlott et al., 2006; Schwitalla et al., 2008), and PRINCE in 2006 (Groenemeijer et al., 2009; Trentmann et al., 2009), which focused mainly on the understanding of surface processes, secondary circulation systems, and initiation of convection. However, the relationship between these processes and QPF had not been studied in detail before it was addressed by COPS. 
A visionary field campaign striving for a high impact in atmospheric sciences cannot be realized without considerable funding and extensive international collaboration. The Priority Program PQP (Hense and Wulfmeyer, 2008) of the DFG provided a platform to prepare and perform COPS, which took place from June to August 2007. We interlinked COPS with a number of international projects and programmes related to QPF, so that within the preparatory phase of COPS a strong international collaboration emerged. A particularly close collaboration was established with the WWRP FDP D-PHASE (Rotach et al., 2009a,b) and with the US ARM Programme. COPS was endorsed as an RDP of WWRP and the COPS field phase was carried out as an international effort with about 300 scientists from eight countries in the field.

This paper is organized as follows. In section 2, the COPS region and its climatology are presented. Precipitation events are defined and characterized with respect to forcing conditions. The scientific goals and the measurements strategy including the set up of observing systems are presented in section 3. Section 4 illustrates the mission performance and research highlights. Applications of the sensor synergy are presented during IOP 8b, an air mass convection case, and IOP9c, a high-impact weather case, and by first model verification results. In section 5 , a summary and an outlook with respect to future work are given demonstrating that COPS scientists have just started to harvest the large data set.

\section{Weather and climate in the COPS region}

\subsection{Orography and land use}

Figure 1(c) shows the COPS area, which is located in central Europe and covers southwestern Germany/eastern France between 6 and $11^{\circ} \mathrm{E}$ and between 47 and $50^{\circ} \mathrm{N}$. The region has a typical midlatitude moderate climate, characterised by a westerly flow with rainfall associated with frontal systems in winter and more convective precipitation in summer.

Dominant orographic features are the low-mountain regions of the Vosges mountains, the Black Forest, and the Swabian Jura. In the south, the domain is bordered by the Swiss Jura mountains and the Alps. The highest mountains are the Grand Ballon $(1424 \mathrm{~m})$ in the Vosges and the Feldberg $(1493 \mathrm{~m})$ in the Black Forest. The highest peak in the northern part of Black Forest is the Hornisgrinde $(1163 \mathrm{~m})$, located northwest of the city of Freudenstadt. The low-mountain areas are separated by several valleys such as the Belfort Gap south of the Vosges mountains, the Rhine valley between the Vosges and Black Forest, and the High Rhine area, the gap between the southern Black Forest and the northeastern section of the Swiss Jura.

The resulting mesoscale flow regimes are controlled by the depth and orientations of the Vosges mountains and the Black Forest, which run from southsouthwest to northnortheast, and the more northeasterly oriented Swabian Jura. Furthermore, the shape and orientation of the valleys is important, since these can lead to splitting and channelling of the flow, to gap flows, and to blocking of the flow by the Alps. It is important to understand the basic features of the mean flow and its splitting and/or channelling on the meso-gamma scale, as this has significant influence on the development and location of convergence lines. (a)

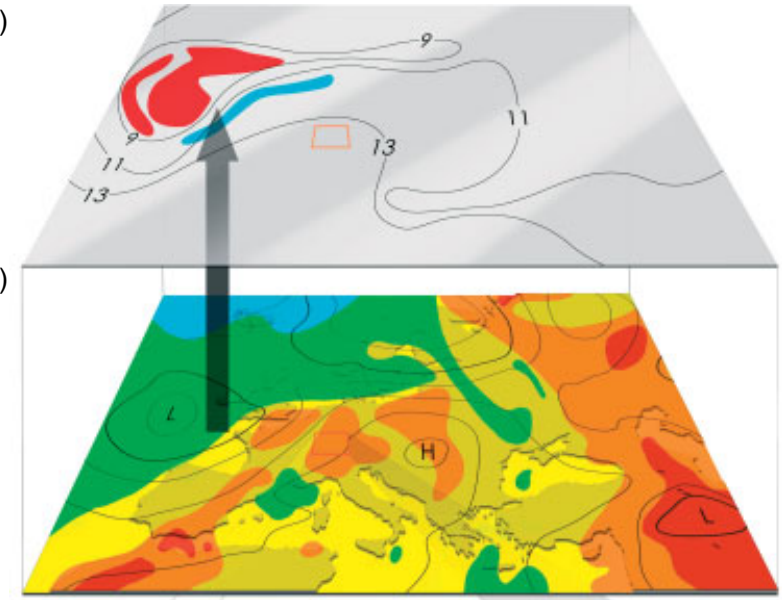

(c)

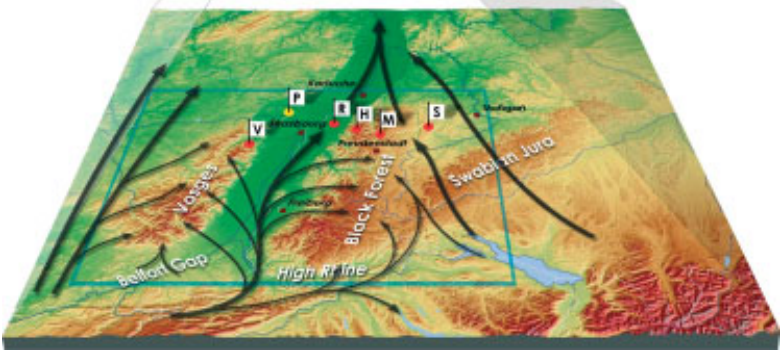

Figure 1. The relation between different forcing conditions leading to CI in midlatitudes during a typical air-mass convection case. (c) The COPS domain with its most important orographic features and flow pattern. The green box indicates the COPS mesoscale target area. The red dots show a transsect of five temporary supersites where a synergy of different remote-sensing instruments and in situ sensors was operated. The orange dot is the POLDIRAD radar site (P). (b) The colour shading shows a typical distribution of $\theta_{e}$ at $850 \mathrm{hPa}$ from low values (green, yellow) to high values (orange, red), and black contours show the geopotential height of the $850 \mathrm{hPa}$ pressure surface. (a) Potential vorticity on the $315 \mathrm{~K}$ surface. Red values $>2$ PVU, blue values $<0.5$ PVU. The contours indicate the tropopause height $(\mathrm{km})$.

Details of thermally induced slope and valley flows are also influenced by land-surface properties and heterogeneity. In the Rhine valley and the smaller valleys extending into the orographic terrain, the main land-use classes are agricultural $(48 \%)$, woodland $(37 \%)$, and water $(1 \%)$. The other $14 \%$ are urban areas, vineyards, sand, fens, and moor. In the Vosges and the Black Forest, the land use is dominated by deciduous and coniferous woodlands. The areas of Stuttgart, Karlsruhe, and Strasbourg are dominated by urbanized and industrialized areas. Besides these three major cities, there is also a dense population in the Rhine valley and in the Neckar valley south of Stuttgart.

\subsection{Precipitation amounts and patterns and their relation to forcing conditions in summer}

It is important to study the large-scale weather situations associated with strong precipitation in the COPS regions. A number of events were examined based on a simple climatological analysis during the period 1996-2003 when at least $25 \mathrm{~mm}$ of precipitation occurred. Further details are presented in the COPS SOD (Wulfmeyer and Behrendt, 2007). In order to identify characteristic weather patterns, these days were classified according to the 16 categories of the DWD GWA (Bisolli and Dittmann, 2001), which categorises the synoptic flow over Germany. The implications of this classification for convection in the COPS region were 
explored by looking at weather charts for 20 individual events. The ten days with highest rainfall amounts with and without reported lightning were considered to identify whether there was a significant chance of severe precipitation not associated with convection. However, in the events examined, the precipitation appeared on satellite imagery to be mainly convective, even when embedded in frontal lines. We concluded from this analysis that there are three characteristic patterns of large-scale flow associated with heavy precipitation in the COPS region:

(i) Forced/frontal: typically a frontal line with embedded convection in a region of large-scale lifting. The precipitation appears to be initiated by the large-scale forcing, with orographic modification of the flow and surface fluxes playing a secondary role.

(ii) Forced/non-frontal: synoptic-scale lifting, but no surface front, so that convection breaks out over a wider area. There is significant low-level flow, so orographic forcing is likely to be important, and surface fluxes may also play a role.

(iii) Air-mass convection (non-forced/non-frontal): occurring in a region of high pressure with no evidence of large-scale forcing at upper or lower levels. Since the low-level flow is also weak, surface fluxes may be dominant in initiating convection.

In the present sample, the most common type was upperlevel forcing without a low-level front (type (ii)), the second was frontal (typically embedded convection, but stratiform could not be ruled out, type (i)), and the third was air-mass convection in a high pressure area (type (iii)). In spite of the fact that there may also be more complex combinations of forcing, these categories turned out to be very useful for the preparation of COPS missions.

The relevant processes and scales and their interactions are depicted in Figure 1. This figure is based on the meteorological situation of COPS IOP8b, a case of airmass convection in the COPS region, but with all of the relevant processes present in the larger European area. A reasonable characterisation of the environmental conditions favourable for convection can be obtained by looking for indicators of forcing mechanisms at various levels in the atmosphere. Beginning in the upper levels, large-scale destabilisation of the atmospheric column can be induced by synoptic-scale ascent causing cooling and increasing CAPE. The upper-level flow is compactly described by the PV field, as seen, for example, on the $315 \mathrm{~K}$ isentropic surface (Figure 1(a)). Large-scale ascents creating regions of instability are associated with maxima of PV advection along stream trajectories. The vertical arrow in Figure 1 points to a typical region.

In the lower troposphere, convection is favoured by advection of warm moist air that acts in two ways. Increased boundary-layer moisture implies larger CAPE for lifted air parcels, while higher equivalent potential temperature $\theta_{\mathrm{e}}$ above the boundary layer reduces buoyancy loss due to entrainment, making deep convection more probable. $\theta_{\mathrm{e}}$ values of $50^{\circ} \mathrm{C}$ generally favour deep convection, and those above $55^{\circ} \mathrm{C}$ indicate severe thunderstorms in the domain. Figure 1(b) shows $\theta_{\mathrm{e}}$ on the $850 \mathrm{hPa}$ surface and its geopotential height, indicating the advection of warm moist air into the COPS region from the Mediterranean ahead of the upper-level trough over the Atlantic Ocean.
In the case of air-mass convection, the forcing is additionally controlled by low-level wind and moisture convergence caused by channelling, flow splitting and thermally induced flows due to orography (Figure 1(c)). During air-mass convection, low-level flow is typically from the southwest. Flow splitting and channelling in the Rhine valley may lead to the development of convergence lines. Their exact locations depend on the strength and interaction of the basic flow and the valley and slope flows. As convection is mainly driven by surface conditions, a strong diurnal cycle of convection and precipitation can be expected. Whether the COPS domain is under the influence of non-forced/non-frontal, weakly forced, or forced-frontal conditions depends on the relative locations and interaction of upper-level PV structure, advection of mid-level $\theta_{\mathrm{e}}$, and low-level orographic flow. During weakly forced and forcedfrontal situations in summer, prefrontal outflow boundaries as well as prefrontal and secondary convection have also to be studied. Additionally, in widespread areas of relatively low surface pressure gradient, air-mass convection can result in MCSs, which themselves can generate lower-tropospheric depressions with frontal systems (Corsmeier et al., 2011; Smith et al., 2011, pers. comm.).

Climatologies of CI confirm the expected diurnal cycle reaching a maximum likelihood of CI around 1000-1100 UTC (section 5.3.1). Unfortunately, we are not aware of climatological analyses of the diurnal cycle of precipitation in central Europe (other than for Germany; Paulat et al., 2008), but spatial distributions of precipitation have been studied in detail (Frei and Schär, 1998; also section 5.3.1). Precipitation patterns are influenced by orography to a large extent, resulting in maximum amounts of precipitation in the low-mountain ranges as well as in the Alpine foothills and main ranges. Minima are detected on the lee side of the lowmountain ranges such as the Rhine valley. The amount of precipitation and its modulation by the orography decreases from June to August. The analysis of these structures is only possible with dense precipitation networks including intensive data quality control.

\section{Scientific goals, measurement strategy, and instru- ment set-up}

\subsection{Science goals}

In a nutshell, the main objective of COPS is the identification of the physical and chemical processes responsible for the deficiencies in QPF in low-mountain regions. These processes were investigated as a function of the forcing conditions in order to improve model initialisation and physics, particularly addressing the poor skill of NWP models. More precisely, the overarching goal of COPS reads: Advance the quality of forecasts of orographically induced convective precipitation by $4 \mathrm{D}$ observations and modelling of its life cycle.

Several hypotheses developed in relation to this goal are introduced in Wulfmeyer et al. (2008). These hypotheses mainly focus on the role of large- and small-scale forcing leading to CI and the organization of convection. Further hypotheses deal with the role of atmospheric variables such as WV and with methodological issues such as advanced data assimilation in combination with new observations. Further details can be found in the SOD (Wulfmeyer et al., 2005) and the Field Report (Wulfmeyer and Behrendt, 2007). 
COPS research has been organized in four WGs, namely on CI, ACM, PPL, and DAP. Detailed lists of their science goals are found in the COPS Field Report (Wulfmeyer and Behrendt, 2007).

The WG CI focuses on high-resolution observations and modelling of convection in complex terrain (Kottmeier et al., 2008). Dynamical and thermodynamical theories are applied to understand the complex flow on various interacting scales and the related moisture variability in order to understand the timing and location of CI. Also radiative effects of aerosols are considered in close collaboration with WG ACM. Key processes leading to CI, such as the formation of convergence lines and their interaction with processes on coarser and finer scales, are investigated and compared with the performance of convection-permitting models. Simulations of CI are related to the windward-lee effect as well as to phase errors in the simulation of precipitation.

The WG ACM explores the relationship between aerosol properties and cloud microphysics in the COPS lowmountain region. For instance, current studies address the question of whether sub-cloud aerosol variability affects convective precipitation. The relation between cloud turbulence and condensation, coalescence, aggregation and thus precipitation is a further subject of investigation. While of extreme importance for midlatitude precipitation processes, the issue of ice formation is one of the most difficult ones to be solved. Therefore, ice-related science questions are more exploratory in nature than other issues addressed by ACM and focus on the correlation between measurable aerosol properties (e.g. depolarization) and ice formation. Obviously, the overlap of these subjects with science questions addressed by major climate research programs is quite significant.

The WG PPL investigates the role of orography for the development and organization of convective cells. A critical point is the distribution of condensed water into different hydrometeor categories (cloud water and ice, graupel, snow, rain water) where large differences between mesoscale model results have been noted. Key topics are the triggering, evolution or lee-side suppression of convective cells. Furthermore, embedded convection triggered by orography as well as the role of orographic flow on the formation and propagation of multi- or super-cells or even MCSs are foci of the WG PPL. An additional purpose of the measurements was to confirm or deny the following hypothesis: The life cycle of single cells is affected by orography, but not that of larger systems. Moreover, cloud-precipitation microphysics has been studied in order to analyse models with respect to systematic errors in QPF.

The WG DAP explores the impact of different observations for improving QPF. Data assimilation is the key to distinguishing between different error sources, namely errors due to initial fields and errors due to parametrization, as the model can be forced to reduce forecast uncertainties due to initial fields. Therefore, data assimilation is an essential tool for the modelling-related research activities of the COPS community. Furthermore, using a variety of mesoscale models in combination with ensemble forecasting, studies on the predictability of convective precipitation can be performed. The goal is to quantify and to extend the limits of predictability of convection through high-resolution ensemble forecasting and advanced data assimilation.
Multi-model simulations during a field campaign are extremely demanding. During COPS, this was realised very successfully by way of collaboration with the WWRP FDP DPHASE (Rotach et al., 2009a). From June to November 2007, within D-PHASE, a huge multi-model ensemble consisting of ensemble forecast systems and deterministic models was operated in the D-PHASE domain, which encompassed the COPS region. For a specific set of models, high-resolution simulations were performed specifically in the COPS domain (Wulfmeyer et al., 2008; Arpagaus et al., 2009; Rotach et al., $2009 a, b)$. This paved the way for systematic analyses of a wide set of models, data assimilation systems, ensemble strategies and verification techniques, both within selected case-studies and longer measurement periods.

\subsection{Generic measurement strategy}

The ambitious goal of COPS - to advance the understanding of the precipitation process chain and the resulting precipitation patterns dependent on the strength and interaction of forcing mechanisms (Figure 1) - required a sophisticated design and coordination of observing systems within different domains. During air-mass convection, large-scale upstream observations were considered less important, whereas detailed observations were necessary in a mesoscale region centred in the COPS domain in combination with specific observations of thermodynamic flows. The observation of squall lines, fronts, and their modification by orography called for the presence of observing systems not only in the COPS domain but also upstream of the front in specific target areas. Details of the flow within and around the frontal system are given by the mesoscale pressure field, which necessitated observations in a mesoscale domain centred in the COPS region. Simultaneously, thermodynamic slope and valley flows had to be observed with great detail as these were expected to combine with the mesoscale flow to determine the development of specific convergence lines with enhanced probability of deep and secondary convection.

Similar requirements for observations are set by weakly and strongly forced convection. In both cases, large-scale upstream conditions needed to be observed before an unstable upper-level air mass reached the COPS domain, possibly initiating deep convection. Again, the mesoscale flow and the thermodynamic properties of the air mass around the COPS low-mountain region were observed in combination with a more detailed regional study of slope and valley flows.

Consequently, three domains were defined where the observations were performed. A large-scale target region for upstream observations, which extended up to $1000 \mathrm{~km}$ upstream and up to $48 \mathrm{~h}$ before the expected convective event. The COPS mesoscale target area covered about $200 \mathrm{~km} \times 300 \mathrm{~km}$ of the central observational region (Figure 1(c)). Observations in this region were essential for improved characterisation of the inflow in the COPS region from ground to the upper troposphere. Finally, small-scale target regions were defined for observing thermodynamically induced slope and valley flows as well as corresponding thermodynamic variables and microphysics within the lowmountain Vosges and Black Forest regions.

For the coordination of the observations in these regions during different forcing conditions, each COPS IOP was separated into four phases in order to cover the whole chain 
of processes responsible for the development of convection and precipitation. Phase 1 was defined by a pre-convective situation. During Phase 2, CI was expected and during Phase 3 the development and organization of convection and precipitation took place. Phase 4 was the period where the decay of convection and precipitation was expected. According to the forcing, during these phases, coordinated measurements in the target regions were performed which are described in detail in the COPS Field Report.

\subsection{Instrumentation}

3.3.1. Combination and coverage of instruments in coordination with other campaigns

The generic measurement strategy of COPS covering the different domains and phases required a combination of measurements from networks, aircraft, specific measurement sites, and satellites using a synergy of in situ and remote-sensing systems. The instruments and their locations were selected for studying the key errors (identified in section 1), such as the windward-lee effect. Furthermore, the selection of the site was based on previous knowledge of specific locations of CI mainly due to typical locations and formations of orographically induced convergence lines (Figure 1). It was decided to set up a west-east oriented line of supersites. Gaps around these sites were closed with satellite and aircraft observations as well as an increased density of the network in order to maximise the likelihood of the observation of pre-convective conditions leading to convergence and CI. Additional activities for optimizing the combination of instruments with respect to their error characteristics were not performed. The focus was set on the deployment of the best available active and passive remote-sensing systems with minimum retrieval errors and maximum range, if possible with scanning capability, in order to avoid sub-optimal observations of CI and precipitation events.

COPS observations can be compared with results during other seasons and in other regions. This became possible by the operation of the US AMF at one of the major measurement sites in the Black Forest during March to December 2007, which provided multi-sensor measurements directly in the COPS domain. Furthermore, COPS was imbedded in a one-year GOP, during which operationally available data in Germany were collected (Crewell et al., 2008). Additional observing systems were operated by collaboration with the TRACKS campaign of the German Helmholtz Research Centres. Upstream measurements were realised by coordination with the first summertime ETReC2007.

\subsubsection{Networks and mobile teams}

Central Europe is covered by several agencies measuring meteorological data and in particular precipitation. Figure 2 shows the data density of various surface precipitation data networks in Europe (Figure 2(a)) and in the COPS domain (Figure 2(b)). Increasing the density of precipitation data is crucial for the accurate determination of representative precipitation values in specific domains and for production of gridded datasets. A consistent weather station dataset has been realized by an effort of the UV and $\mathrm{UHOH}$, the socalled Joint D-PHASE-COPS (JDC) dataset (Gorgas et al.,
2009), which is extensively applied for process studies and model verification. In the close vicinity of supersite $S$, a network of more than 100 automated weather stations was installed by the UV (Figure 2(b)).

Networks of soil moisture and temperature, energy balance, and turbulence stations were set up for studying the role of land-surface exchange processes on thermally induced flows and convection initiation. The locations were chosen so that different soil properties, landsurface coverage, and orographic features were probed and precipitation was measured at the same sites. Care was taken that the process studies could benefit from their synergy: soil moisture measurements were performed at all turbulence and energy balance stations and supersites (Figure 3). At Hornisgrinde, Achern, and Murg valley, irradiance measurements allowed cloud macrophysical property retrievals by radiative flux analyses (Long et al., 2006; Long and Turner, 2008). In order to derive the mass and moisture budgets (convergence) of the anabatic wind regimes, sodars as well as turbulence and wind meteorological stations were installed at six different locations (Figure 3).

Another key dataset was the increased-density COPS GPS network (Figure 3). GPS processing systems (e.g. Dick et al., 2001; Gendt et al., 2004) estimated several atmospheric parameters, such as STD, ZTD, and IWV under all weather conditions. STD data were available within short processing times for real-time data assimilation (Zus et al., 2008; Bauer et al., 2010). Special effort has been made to have GPS stations at both mountain crests and in valley bottoms of the Vosges and Black Forest regions. GPS tomography will be applied to retrieve 3D WV fields (e.g. de Haan and van der Marel, 2008; Champollion et al., 2009).

In and around the central COPS region, radio soundings were routinely performed by DWD at Stuttgart and Munich, by MeteoSwiss at Payerne, and by Météo-France at Nancy at 0000 and 1200 UTC, which were intensified upon request during IOPs. During the operation of the AMF from 1 April to 31 December 2007, six-hourly soundings were performed and distributed via the GTS. During COPS IOPs, soundings were performed with a resolution of $3 \mathrm{~h}$ at all supersites as well as at the KIT and the Burgundische Pforte sites.

Two operational lightning-detection networks covering Central Europe were available for COPS. The BLIDS system is operated by Siemens AG and the LINET system by the UM together with Nowcast GmbH. The network was locally extended by four DLR LINET stations around the DLR POLDIRAD site (Figure 3).

In the COPS mesoscale target region, eight operational Doppler C-band radars (DWD at Neuheilenbach, Feldberg, Frankfurt, Türkheim; KIT at Karlsruhe; MeteoSwiss at Albis; Météo-France at Nancy, Montancy) are operated. This radar network provided a complete coverage of the COPS region with maximum ranges from the radars of about $150 \mathrm{~km}$. However, shielding of the radar beams by orography leads to a considerably reduced coverage in the complex orography of the mesoscale COPS target region. In order to increase the coverage, several additional radar systems were deployed. The POLDIRAD of DLR Oberpfaffenhofen, a C-band polarisation Doppler radar in the Rhine valley, the local area X-band radar of LaMP in the Vosges (van Baelen et al., 2009), as well as the polarisation S-band radar TARA of TUD and the vertically pointing 


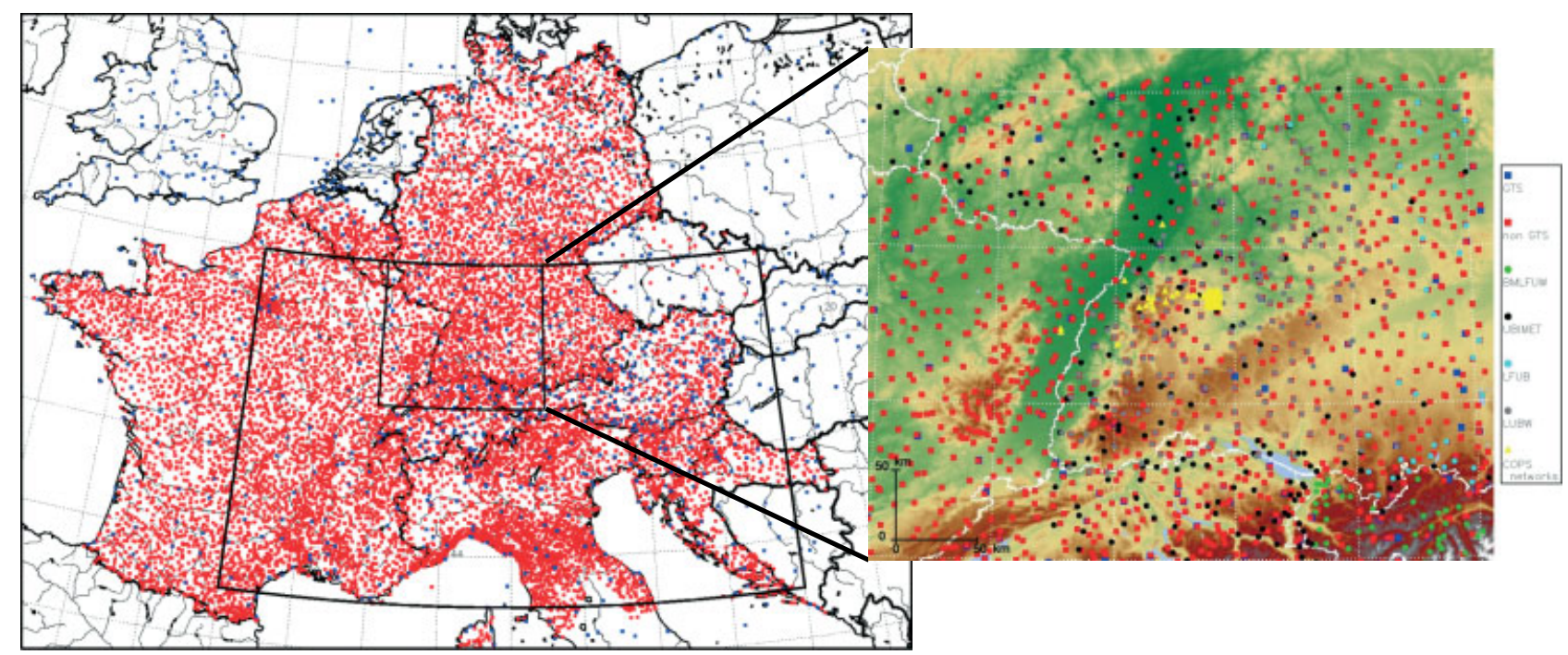

Figure 2. (a) The European surface observations network of GTS (blue dots) and non-GTS stations (red dots) demonstrating the inhomogeneity and the importance of increasing the density beyond GTS. (b) Expansion of the COPS region $\left(6-11^{\circ} \mathrm{E}, 47-50^{\circ} \mathrm{N}\right)$ showing the increase in density of the surface and precipitation networks by different agencies to supplement the COPS network (from the Universities of Bayreuth, Innsbruck, and Vienna as well as IMK). Abbreviations are given in the appendix.

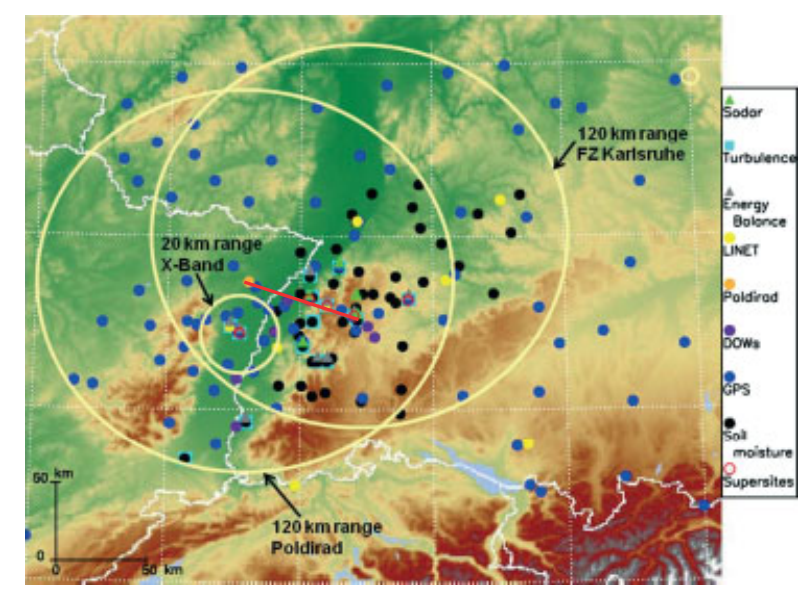

Figure 3. Main part of the COPS observing network $\left(47-50^{\circ} \mathrm{N}\right.$, $\left.6-11^{\circ} \mathrm{E}\right)$. The yellow circles show the range of the COPS radar network, demonstrating its overlap in the central part of the domain. The red line indicates the excellent overlap of RHI scans of POLDIRAD with vertical measurements over the supersites R, H, and M (see also Figure 4).

X-band Doppler radar of $\mathrm{UHOH}$ at Hornisgrinde in the northern Black Forest. Their coverage is plotted in Figure 3. Furthermore, two US DOWs were operated in several key regions where low-level flows in the valleys and towards the mountain slopes were expected to lead to CI (also Figure 3 ). Their operation modes were decided one day ahead of a COPS IOP by the COPS Operations Centre. At locations expected to be critical for CI in the northern Black Forest and its vicinity, a similar procedure was executed for the operation of mobile meteorological stations and for the launching of radiosondes before, within, and behind convective cells.

\subsubsection{Supersites}

A special component of COPS was the deployment of sensor synergy in small-scale target regions at five temporary observatories, i.e. so-called supersites (Table I; Figure 1(c)). In order to observe convergence above the ridges and to study windward/lee effects, the supersites were oriented along a transect through the COPS mesoscale target region at the Vosges low-mountain range (supersite V), Rhine Valley (R), Hornisgrinde mountain site $(\mathrm{H})$, Murg valley $(\mathrm{M})$, and Deckenpfronn close to Stuttgart (S). The supersites R, H and $M$ were co-aligned with POLDIRAD so that one RHI scan of this radar sampled the atmosphere above these supersites at distances of $\sim 35,45$, and $60 \mathrm{~km}$, respectively. This strategy supported the supersite remote-sensing measurements with, e.g., estimates of the distribution of hydrometeors in precipitation.

At all supersites, instruments for clear air, cloud, and precipitation measurements were combined: different types of remote-sensing instruments (lidar systems, cloud radars, precipitation radars, radiometers), in situ research instruments (e.g. for aerosol analysis), and sensors of the above-mentioned networks (radiosonde stations, soil moisture sensors, turbulence and energy balance stations, weather stations, GPS receivers). The nine-month measurements of the AMF provided the backbone of the instrumentation at supersite M (Miller and Slingo, 2007, give a complete list of instruments). Figure 4 gives an overview of the supersite instrumentation; further details can be found in the COPS Field Report (Wulfmeyer and Behrendt, 2007). Table II presents an overview of the different lidar systems operated during COPS with their variety of special measurement properties, partly with scanning capability, ranging from Doppler wind measurements, to $\mathrm{WV}$ and temperature measurements to aerosol microphysics. The scanning remote-sensing instruments were synchronized and different types of scan patterns were made depending on the scope of each IOP.

\subsubsection{Aircraft}

In total, ten aircraft were operated in the mesoscale target region and for upstream targeting. An overview of their characteristics is presented in Table III. The DLR Falcon performed several targeting flights; otherwise various mapping missions for studying WV heterogeneity and fluxes in the COPS region were executed. These missions 
Table I. Locations of COPS Supersites and POLDIRAD site.

\begin{tabular}{lll}
\hline Site & Location & Altitude (m amsl) \\
\hline Supersite S (Stuttgart), Airport Deckenpfronn & $8.813^{\circ} \mathrm{E}, 48.635^{\circ} \mathrm{N}$ & $\sim 600$ \\
Supersite M (Murg Valley), AMF site, Heselbach & $8.405^{\circ} \mathrm{E}, 48.545^{\circ} \mathrm{N}$ & $\sim 500$ \\
Supersite H (Hornisgrinde), Hornisgrinde & $8.204^{\circ} \mathrm{E}, 48.604^{\circ} \mathrm{N}$ & $\sim 1150$ \\
Supersite R (Rhine Valley), Achern & $8.066^{\circ} \mathrm{E}, 48.638^{\circ} \mathrm{N}$ & $\sim 140$ \\
Supersite V (Vosges mountains) & $7.545^{\circ} \mathrm{E}, 48.443^{\circ} \mathrm{N}$ & $\sim 151$, valley: Meistratzheim \\
& $7.473^{\circ} \mathrm{E}, 48.483^{\circ} \mathrm{N}$ & $\sim 355$, mountain; Bishenberg \\
POLDIRAD, Waltenheim sur Zorn & $7.610^{\circ} \mathrm{E}, 48.739^{\circ} \mathrm{N}$ & $\sim 250$ \\
\hline
\end{tabular}

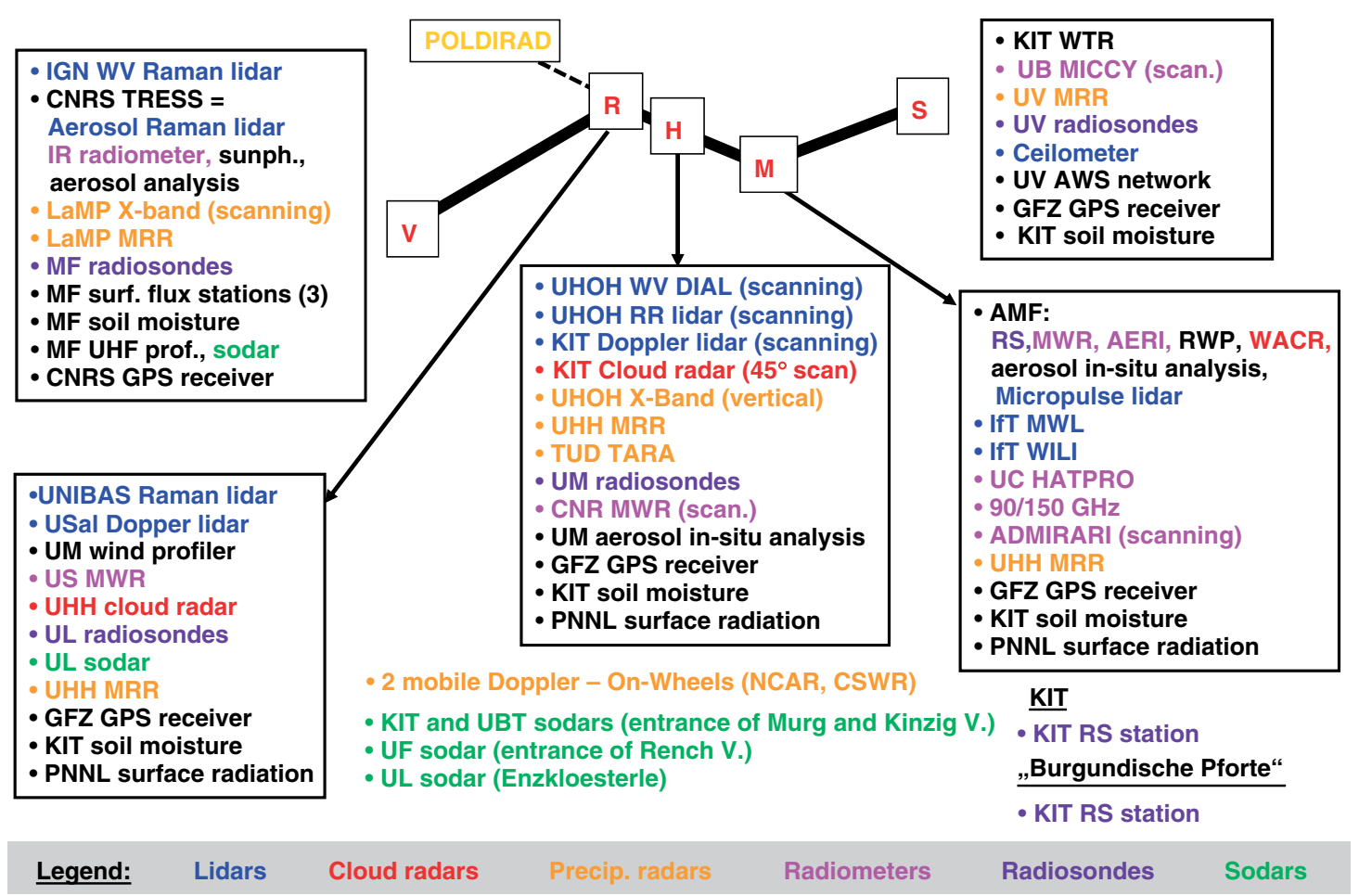

Figure 4. Supersite instrumentation. All abbreviations are given in the appendix.

were coordinated with similar flight tracks performed with the French SAFIRE Falcon. For low-level boundarylayer observations, the DO-128 and an Ultralight aircraft were available. Particularly, turbulence measurements by the DO-128 aircraft provided valuable data for spatial interpolation of ground-based systems at the supersites. In connection with TRACKS, a Learjet and a Zeppelin both equipped with chemical sensors observed the transformation of chemical species in city plumes and in convective systems. Funded by EUFAR, the SAFIRE ATR-42 and the Partenavia were provided for in situ measurements of aerosol-cloud-precipitation microphysics, and the Ultralight for aerosol characterisation. Whereas most of the aircraft followed predefined tracks, the BAE 146 was allowed to operate very flexibly in a defined box over the northern Black Forest. An example of a regular mapping pattern in long sections parallel to the Rhine valley is given in Figure 5. Continuous WV profiles above and between isolated cumulus clouds were sampled by the airborne WALES system of DLR Oberpfaffenhofen juxtaposed to the positions of ground-based WV lidar systems at the supersites. The synergy of these observations is extensively applied for process studies, e.g. Kiemle et al. (2011) and Behrendt et al. (2011).

\subsubsection{Satellites}

For the second time after MAP in autumn 1999, EUMETSAT provided the RSS for a field campaign in Europe. The MSG-8 satellite was operated in the RSS mode between $15^{\circ} \mathrm{N}$ and $69^{\circ} \mathrm{N}$ with a time resolution of $5 \mathrm{~min}$ (Aoshima et al., 2008 show a detailed table of operations). The spatial resolution of the images depends on the wavelength of the MSG channel resulting in $\approx 3 \mathrm{~km}$ for the visible and infrared and about $1 \mathrm{~km}$ for the high-resolution visible channel. The RSS was provided in real time to the COPS Operations Centre for mission guidance. Three-channel composites of RSS data were processed by DLR for the full duration of COPS.

\subsubsection{Upstream observations}

The first summertime ETReC (2007) enhanced the COPS programme through two activities: daily predictions of sensitive (i.e. optimal) locations for supplementary observations, and the deployment of additional observations upstream of the COPS region. Three centres (MétéoFrance, ECMWF, UBal) provided a total of five different sensitivity calculations, including moist singular vectors, 
Table II. Lidar systems operated during COPS including their locations, supporting institution, measured parameters, and relevant references.

\begin{tabular}{|c|c|c|c|c|c|c|c|c|}
\hline \multirow[t]{2}{*}{ Instrument } & \multirow[t]{2}{*}{ Type } & \multirow[t]{2}{*}{ Institution } & \multicolumn{5}{|c|}{ Measured parameters } & \multirow[t]{2}{*}{ Reference } \\
\hline & & & WV & Temperature & Wind & $\mathrm{PBC}$ & Aerosols & \\
\hline \multicolumn{9}{|l|}{ Airborne } \\
\hline DIAL & $\begin{array}{l}\text { WV Differen- } \\
\text { tial Absorption } \\
\text { lidar }\end{array}$ & DLR & $\mathrm{X}$ & & & & $\mathrm{X}$ & Wirth et al. (2009) \\
\hline Doppler Lidar & $\begin{array}{l}2 \mu \mathrm{m} \text { Doppler } \\
\text { lidar, scanning }\end{array}$ & DLR & & & $\mathrm{X}$ & & $\mathrm{X}$ & \\
\hline $\begin{array}{l}\text { DIAL } \\
\text { (INSU/CNRS) }\end{array}$ & $\begin{array}{l}\text { WV Differen- } \\
\text { tial Absorption }\end{array}$ & SAFIRE & $\mathrm{X}$ & & & & $\mathrm{X}$ & Bruneau et al. (2001) \\
\hline $\begin{array}{l}\text { LEANDRE } 2 \\
\text { (LATMOS, } \\
\text { DT/INSU, } \\
\text { INSU/CNRS) } \\
\text { Supersite H }\end{array}$ & lidar & & & & & & & \\
\hline DIAL & $\begin{array}{l}\text { WV Differen- } \\
\text { tial Absorption } \\
\text { lidar }\end{array}$ & $\mathrm{UHOH}$ & $\mathrm{X}^{*}$ & & & & $\mathrm{X}^{*}$ & Behrendt et al. (2009) \\
\hline RRL & $\begin{array}{l}\text { Rotational } \\
\text { Raman lidar, } \\
\text { scanning }\end{array}$ & $\mathrm{UHOH}$ & & $\mathrm{X}^{*}$ & & $\mathrm{X}$ & $\mathrm{X}^{*}$ & Radlach et al. (2008) \\
\hline Wind Tracer & $\begin{array}{l}2 \mu \mathrm{m} \text { Doppler } \\
\text { lidar, scanning }\end{array}$ & KIT & & & $\mathrm{X}^{*}$ & & $\mathrm{X}^{*}$ & \\
\hline \multicolumn{9}{|l|}{ Supersite M } \\
\hline MWL & $\begin{array}{l}\text { Multi- } \\
\text { wavelength } \\
\text { Raman lidar }\end{array}$ & If T & $\mathrm{X}^{\dagger}$ & $\mathrm{X}^{\dagger}$ & & $\mathrm{X}$ & $\mathrm{X}^{*}$ & \\
\hline $\begin{array}{l}\text { Micropulse } \\
\text { lidar }\end{array}$ & $\begin{array}{l}532 \quad \mathrm{~nm} \\
\text { backscatter } \\
\text { lidar }\end{array}$ & ARM & & & & & $\mathrm{X}^{*}$ & \\
\hline WiLi & $\begin{array}{l}2 \mu \mathrm{m} \text { Doppler } \\
\text { lidar, scanning }\end{array}$ & IfT & & & $\mathrm{X}$ & & $\mathrm{X}$ & \\
\hline \multicolumn{9}{|l|}{ Supersite $R$} \\
\hline BASIL & $\begin{array}{l}\text { Multi- } \\
\text { wavelength } \\
\text { Raman lidar }\end{array}$ & UNIBAS & $\mathrm{X}^{*}$ & $\mathrm{X}^{*}$ & & $\mathrm{X}$ & $\mathrm{X}^{*}$ & \\
\hline Doppler lidar & $\begin{array}{l}2 \mu \mathrm{m} \text { Doppler } \\
\text { lidar, scanning }\end{array}$ & USal & & & $\mathrm{X}^{*}$ & & $\mathrm{X}^{*}$ & \\
\hline \multicolumn{9}{|l|}{ Supersite S } \\
\hline $\begin{array}{l}\text { Ceilometer } \\
\text { Supersite V }\end{array}$ & CT25K type & UB & & & & & $\mathrm{X}$ & \\
\hline $\begin{array}{l}\text { Raman lidar } \\
\text { (IGN/LAREG, } \\
\text { LATMOS, } \\
\text { INSU/CNRS) }\end{array}$ & $\begin{array}{l}\text { WV Raman } \\
\text { lidar }\end{array}$ & CNRS & $\mathrm{X}$ & & & & $\mathrm{X}$ & \\
\hline $\begin{array}{l}\text { TReSS } \\
\text { (INSU/CNRS, } \\
\text { LMD) }\end{array}$ & $\begin{array}{l}\text { Aerosol } \\
\text { Raman lidar }\end{array}$ & CNRS & & & & $\mathrm{X}$ & $\mathrm{X}$ & \\
\hline
\end{tabular}

Abbreviations of instruments and responsible institutions are given in the appendix.

* denotes $24 \mathrm{~h}$ measurements; ${ }^{\dagger}$ denotes night-time measuremts.

ETKF, and several versions of adjoint sensitivities. These were collated and made available in real time at a website hosted by DLR, along with forecast products tailored for flight planning.
DWD, KNMI, Météo-France, and MeteoSwiss provided additional radio soundings within the framework of EUCOS. Six-hourly observations were recorded at ten stations upstream and around the COPS domain. On seven 
Table III. Aircraft operated during COPS.

\begin{tabular}{|c|c|c|c|c|c|c|}
\hline $\begin{array}{l}\text { Aircraft, } \\
\text { responsible } \\
\text { institution, } \\
\text { location }\end{array}$ & $\begin{array}{l}\text { Key instruments } \\
\text { (apart from } \\
\text { standard } \\
\text { meteorology) }\end{array}$ & $\begin{array}{l}\text { Contributions } \\
\text { to COPS WGs }\end{array}$ & $\begin{array}{l}\text { Contributions } \\
\text { to Phases } 1-4\end{array}$ & $\begin{array}{l}\text { Contributions } \\
\text { by other } \\
\text { projects linked } \\
\text { to COPS }\end{array}$ & $\begin{array}{l}\text { Operation dates, } \\
\text { flight days, flight } \\
\text { hours }\end{array}$ & $\begin{array}{l}\text { Height } \\
(\mathrm{km})\end{array}$ \\
\hline $\begin{array}{l}\text { Falcon, DLR, } \\
\text { Oberpfaffen- } \\
\text { hofen }\end{array}$ & $\begin{array}{l}\text { WV DIAL, } \\
\text { Doppler lidar, } 57 \\
\text { dropsondes }\end{array}$ & CI, ACM, DAP & $1-3$ & $\begin{array}{l}\text { ETReC2007, D- } \\
\text { PHASE }\end{array}$ & $\begin{array}{l}28 \quad \text { June }-5 \\
\text { August, } 30 \text { days, } \\
45 \mathrm{~h}\end{array}$ & $4-12$ \\
\hline $\begin{array}{l}\text { Falcon, SAFIRE, } \\
\text { Baden Airpark }\end{array}$ & $\begin{array}{l}\text { WV DIAL, } 80 \\
\text { dropsondes }\end{array}$ & CI, ACM, DAP & $1-3$ & $\begin{array}{l}\text { D-PHASE, } \\
\text { EUFAR }\end{array}$ & $\begin{array}{l}10 \quad \text { July-2 } \\
\text { August, } 24 \text { days, } \\
35 \mathrm{~h}\end{array}$ & $\begin{array}{l}5-6,(\mathrm{FL} \\
150)\end{array}$ \\
\hline $\begin{array}{l}\text { DO-128, FZK, } \\
\text { Baden Airpark }\end{array}$ & $\begin{array}{l}\text { Tracer, radiation, } \\
\text { fluxes }\end{array}$ & CI, ACM & $1-3$ & TRACKS & $\begin{array}{l}11 \text { June-31 July, } \\
35 \text { days, } 125 \text { h }\end{array}$ & Up to 7 \\
\hline $\begin{array}{l}\text { BAe-146, } \\
\text { FAAM, Baden } \\
\text { Airpark }\end{array}$ & $\begin{array}{l}\text { Extensive aerosol } \\
\text { and cloud micro- } \\
\text { physics }\end{array}$ & CI, ACM, PPL & $1-3$ & TRACKS & $\begin{array}{l}9 \text { July-27 July, } \\
84 \mathrm{~h}\end{array}$ & Up to 8 \\
\hline $\begin{array}{l}\text { Learjet } 35 \mathrm{~A} \text {, } \\
\text { MPIfC, Hohn }\end{array}$ & Photochemistry & $\mathrm{CI}, \mathrm{ACM}$ & $1-4$ & TRACKS & $\begin{array}{l}16 \text { July-28 July, } \\
3-4 \text { flights }\end{array}$ & $\begin{array}{l}\text { Up to } 13 \\
(\mathrm{FL} 400)\end{array}$ \\
\hline $\begin{array}{l}\text { Zeppelin NT, } \\
\text { FZJ, Baden Air- } \\
\text { park }\end{array}$ & Photochemistry & CI, ACM & $1-2$ & TRACKS & $\begin{array}{l}16 \text { July-31 July, } \\
80 \mathrm{~h}\end{array}$ & $0.02-1.0$ \\
\hline $\begin{array}{l}\text { UltraLight } \\
\text { Schmidtler } \\
\text { Enduro, FZK, } \\
\text { Baden Airpark }\end{array}$ & $\begin{array}{l}\text { Radiation, aerosol } \\
\text { microphysics, } \\
\text { turbulence, fluxes }\end{array}$ & $\mathrm{CI}, \mathrm{ACM}$ & $1-2$ & $\begin{array}{l}\text { TRACKS, } \\
\text { EUFAR }\end{array}$ & $\begin{array}{l}15 \quad \text { June-26 } \\
\text { July, } 8 \text { days, } \\
4-5 \text { h/day, VFR } \\
\text { conditions }\end{array}$ & $0.02-4.5$ \\
\hline $\begin{array}{l}\text { DIMONA, } \\
\text { METAIR, Baden } \\
\text { Airpark }\end{array}$ & $\begin{array}{l}\text { Photochemistry, } \\
\text { tracer, wind and } \\
\text { turbulence }\end{array}$ & $\mathrm{CI}, \mathrm{ACM}$ & $1-2$ & $\begin{array}{l}\text { TRACKS, } \\
\text { EUFAR }\end{array}$ & $\begin{array}{l}16 \quad \text { July-01 } \\
\text { August, } 8 \text { days, } \\
40 \mathrm{~h}\end{array}$ & $0.15-4$ \\
\hline $\begin{array}{l}\text { ATR-42, } \\
\text { SAFIRE, Baden } \\
\text { Airpark }\end{array}$ & $\begin{array}{l}\text { Two PMS-2DC } \\
\text { probes, FSSP } 100 \\
\text { Gerber PMV100 }\end{array}$ & ACM, PPL & & EUFAR & $\begin{array}{l}20 \text { July-29 July, } \\
10 \text { days, } 10 \text { h }\end{array}$ & $0.1-7.5$ \\
\hline $\begin{array}{l}\text { ENVISCOPE } \\
\text { PARTENAVIA, } \\
\text { Baden Airpark }\end{array}$ & $\begin{array}{l}\text { Aerosol and cloud } \\
\text { microphysics }\end{array}$ & ACM, PPL & & EUFAR & $\begin{array}{l}2 \text { July-31 July, } \\
3-4 \text { days, } 7-8 \text { h }\end{array}$ & $\begin{array}{l}\text { Up to } \\
\text { FL120 }\end{array}$ \\
\hline
\end{tabular}

Abbreviations are given in the appendix.

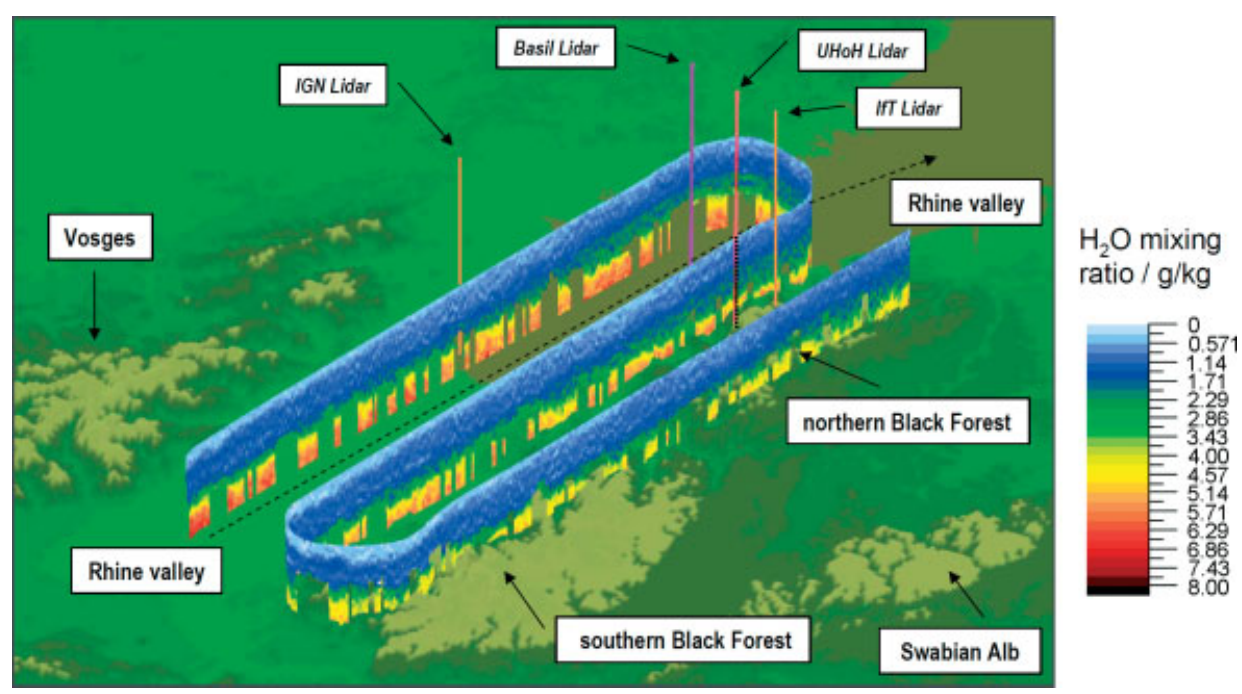

Figure 5. Perspective southeast to northwest view of airborne WV lidar measurements during IOP 12 on 30 July 2007 between 1040 and 1125 UTC. The length $\times$ height of the data curtains is $150 \mathrm{~km} \times 4 \mathrm{~km}$. The topographic heights range from below $150 \mathrm{~m}$ to above $750 \mathrm{~m}$ in increments of $150 \mathrm{~m}$. The positions of ground-based WV lidar systems that were available at four supersites are also indicated by vertical lines. Data gaps below $\approx 2.5 \mathrm{~km}$ are due to attenuation of the laser beam by isolated cumulus clouds. 
days, E-AMDAR sensors (wind, pressure and temperature measurements from European commercial aircraft) were activated in the region $\left(35-55^{\circ} \mathrm{N}, 10^{\circ} \mathrm{W}-10^{\circ} \mathrm{E}\right)$, generating over 4000 additional data points each day. The majority of these additional observations were ingested in the GTS and used in operational weather forecasting. For three events, flights of the DLR Falcon carrying wind and WV lidar systems were made into sensitive regions over France, Spain, and the eastern Atlantic Ocean. Due to the small number of cases, the impact of the additional measurements on forecasts is difficult to determine. However, the unique combination of collocated highresolution wind and WV measurements has enabled Schäfler et al. (2010) to perform a detailed evaluation of moisture transports in the global ECMWF model, showing how the properties of the pre-convective environment were established.

\section{Mission performance and research highlights}

\subsection{Mission coordination and overview}

The COPS Operations Centre was set up in the centre of the COPS domain at Baden Airpark, where the majority of aircraft were stationed. Daily mission planning and selection was guided by a rotating international team of forecasters who had a variety of numerical model guidance at their disposal, with displays partly tailored for COPS. These included global models of ECMWF, DWD, MétéoFrance, and the NCEP, as well as limited-area AROME and COSMO models, and a collection of ensemble-based and deterministic research models operated for D-PHASE. The location and distribution of clouds was important for assessing the timing and location of CI. Since the timing of cloud forecasts is highly uncertain, it was fortunate that data from several radars were available in real time, which were very useful for short-term mission planning and guidance.

For several deterministic models and ensembles, harmonised visualisations of meridional and longitudinal cross-sections, meteograms at key locations such as the supersites, and a multitude of $2 \mathrm{D}$ plots were provided by the $\mathrm{UHOH}$. All these figures $\left(50 \times 10^{6}\right.$ in total $)$ are stored in the data archive. The facility status and operational products of COPS instrumentation were distributed in real time via the COPS webpage to ensure that the instruments addressing key science questions were available during the IOPs.

Table IV gives an overview of the IOPs and SOPs performed within the scope of COPS. Over three months, 18 IOPs with 37 operation days and 8 additional SOPs were performed providing a comprehensive dataset. Particular highlights were IOPs 8b (15 July) and 9c (20 July) where all non-continuous remote-sensing instruments were operated simultaneously, and cases with Saharan dust outbreaks over the COPS domain (e.g. IOP 13, 1-2 August). IOP days were categorized as defined above: air-mass convection, weakly forced conditions, or strongly forced conditions. If a mixture of these forcing mechanisms was detected, this was also indicated. In general, a rather homogeneous mixture of events was found: $35 \%$ air mass, $27 \%$ weakly forced, and $38 \%$ strongly forced convection IOP days.

\subsection{Data archive, quality control, and key data sets}

All COPS data have been stored in an archive of the WDCC $^{\S}$. For research applications, the data are available for the whole atmospheric science community. As far as possible, the observations and the metadata are provided in a harmonized format. Thorough control of the data quality is the fundamental basis of the success of any measurement. In addition to internal quality control and standard calibration, different measurements of the same quantity must also be compared with each other in order to ensure a consistent dataset. This is especially crucial for humidity. Consequently, a part of the operation time of the instrumentation was allocated for intercomparisons.

Intercomparisons have to be as close in space and time as possible to minimize the effects of atmospheric variability (Behrendt et al., 2007a,b). Thus, stacked formation flights of the aircraft carrying remote-sensing instrumentation were performed. In addition to such stacked formation flights, frequent overpasses over the ground-based supersites were also considered when the flight patterns were planned. Frequent overpasses are necessary to identify potential instrumental biases with good accuracy, as the data from the remote-sensing instruments are averaged in space and time and different air masses are sampled during these airborne/ground-based intercomparisons. Results are presented in Bhawar et al. (2011).

These efforts are the basis for the production of highquality datasets for process and data assimilation studies as well as model validation. All remote-sensing data were transformed in a new harmonized data format and provided to the COPS data archive. Gridding of data from surface networks such as the JDC dataset is ongoing and will provide surface wind, $\theta_{\mathrm{e}}$, and humidity fields, as well as precipitation fields. For this purpose, kriging approaches and the VERA were applied (Steinacker et al., 2006). A continuous VERA analysis of the whole year 2007 for Europe has already been performed with resolutions of $1 \mathrm{~h}$ and $8 \mathrm{~km}$, respectively, for the surface atmospheric variables (Gorgas et al., 2009). Gridded IWV fields were constructed from the COPS GPS network by GFZ. GPS tomography is currently being applied for reconstructing 3D WV fields (e.g. Champollion et al., 2009; Reverdy et al., 2009).

\subsection{Process and model verification studies}

\subsubsection{The COPS summer 2007 in perspective}

The COPS dataset permitted a detailed comparison of CI and precipitation statistics with climatologies. Figure 6(a) presents the summertime precipitation climatology based on data and analysis methods of Frei and Schär (1998) and Schwarb et al. (2001). As discussed in section 2.2, the figure confirms the strong influence of orography. Figure 6(b) presents the distribution of precipitation during COPS based on the new JDC dataset and gridded by VERA (Dorninger et al., 2008; Bauer et al., 2011). The COPS summer was significantly wetter than the climatological mean. Otherwise, from June to August in the central low-mountain region, the spatial patterns and a decreasing trend were similar (not

${ }^{\S}$ The data can be accessed via http://cera-
www.dkrz.de/WDCC/ui/BrowseExperiments.jsp?proj=COPS 
Table IV. IOP and SOP days with convection type and most important weather features.

\begin{tabular}{|c|c|c|c|c|}
\hline IOP/SOP & Time period & $\begin{array}{l}\text { Weather } \\
\text { type* }\end{array}$ & $\begin{array}{l}\text { Other } \\
\text { mission }\end{array}$ & Weather development in COPS domain \\
\hline IOP-1a & 5 June, $0400-2000$ & AMC & & Isolated diurnally induced showers \\
\hline IOP-1b & 6 June, $0400-2000$ & $\mathrm{AMC}$ & & $\begin{array}{l}\text { Isolated diurnally induced and clustered } \\
\text { showers }\end{array}$ \\
\hline IOP-1c & 7 June, $0400-2000$ & AMC & & Surface-based convective showers \\
\hline IOP-1d & 8 June, $0400-2000$ & $\mathrm{AMC} / \mathrm{SFC}$ & & $\begin{array}{l}\text { Scattered surface-based diurnally induced } \\
\text { showers }\end{array}$ \\
\hline IOP-2 & 12 June, $0600-1800$ & WFC & & Isolated weak diurnally induced showers \\
\hline IOP $3 a$ & 14 June, $0400-2000$ & WFC & & $\begin{array}{l}\text { Storms followed by a squall line moving } \\
\text { through the Rhine valley }\end{array}$ \\
\hline IOP-3b & 15 June, $0400-1100$ & SFC & & $\begin{array}{l}\text { Widespread cloudiness, no convective } \\
\text { showers }\end{array}$ \\
\hline $\mathrm{IOP}-4 \mathrm{a}$ & 19 June, 0600-2000 & $\mathrm{AMC}$ & & $\begin{array}{l}\text { No convective showers, medium-sized } \\
\text { cumulus over the mountains }\end{array}$ \\
\hline $\mathrm{IOP}-4 \mathrm{~b}$ & 20 June, $0500-2300$ & SFC & & $\begin{array}{l}\text { Diurnally induced showers, initiation of } \\
\text { strong storms east of Freudenstadt and } \\
\text { Feldberg }\end{array}$ \\
\hline IOP-5a & 1 July, 0400-2300 & SFC & & $\begin{array}{l}\text { Synoptically forced southwesterly flow of } \\
\text { moist, warm air; storms NW of the COPS } \\
\text { area }\end{array}$ \\
\hline IOP-5b & 2 July, 0500-2100 & SFC & & $\begin{array}{l}\text { Storms within a polar air mass, intensifi- } \\
\text { cation and linear organisation during the } \\
\text { day }\end{array}$ \\
\hline IOP-6 & 4 July, 0500-2100 & SFC & & Shallow showers during the day \\
\hline IOP-7a & 8 July, 0500-2400 & SFC & & $\begin{array}{l}\text { Large precipitation system with imbedded } \\
\text { convection }\end{array}$ \\
\hline IOP-7b & 9 July, 0000-1800 & SFC & & Isolated weak showers across the COPS area \\
\hline SOP-1a & 12 July 0500 to 13 July 0700 & & EUFAR & \\
\hline IOP-8a & 14 July, $0515-1830$ & AMC & & Shallow convection, no precipitation \\
\hline IOP-8b & 15 July, $0500-1830$ & $\mathrm{AMC}$ & & $\begin{array}{l}\text { Isolated line of towering cumulus clouds east } \\
\text { of the Black Forest, isolated thunderstorm }\end{array}$ \\
\hline SOP-1 & 16 July, $0500-0900$ & & EUFAR & \\
\hline IOP-9a & 18 July, 0800-2000 & SFC & & $\begin{array}{l}\text { Few short-lived surface-based convective } \\
\text { storms east of the Vosges mountains }\end{array}$ \\
\hline IOP-9b & 19 July, $0600-1800$ & SFC & & $\begin{array}{l}\text { MCS moving over COPS region followed by } \\
\text { partially convective precipitation }\end{array}$ \\
\hline IOP-9c & 20 July, $0500-2000$ & SFC & & $\begin{array}{l}\text { MCS moving over COPS area with reacti- } \\
\text { vation of convection on the Black Forest lee } \\
\text { side }\end{array}$ \\
\hline SOP-2 & 21 July, $0600-1600$ & & EUFAR & \\
\hline SOP-3 & 22 July, $0700-1700$ & & EUFAR, TRACKS & \\
\hline IOP-10 & 23 July, $0500-1800$ & SFC & EUFAR, TRACKS & $\begin{array}{l}\text { A large area of precipitation with embedded } \\
\text { convective zones across the COPS area }\end{array}$ \\
\hline SOP-4 & 24 July, $0600-1800$ & & EUFAR, BAE & \\
\hline IOP-11a & 25 July, $0600-1800$ & AMC & EUFAR & $\begin{array}{l}\text { Cumulus convection mostly over the moun- } \\
\text { tains }\end{array}$ \\
\hline IOP-11b & 26 July, $0500-1700$ & $\mathrm{AMC}$ & & Cumulus convection \\
\hline SOP-5 & 28 July, $0900-1400$ & & EUFAR & \\
\hline IOP-12 & 30 July, $0800-1800$ & WFC & & Cumulus convection \\
\hline SOP-6 & 31 July, $1900-2200$ & & EUFAR & \\
\hline IOP-13a & 01 Aug, 0415-2000 & AMC & & $\begin{array}{l}\text { Cloud-free weather under a high-pressure } \\
\text { ridge; Saharan dust outbreak over COPS } \\
\text { domain }\end{array}$ \\
\hline IOP-13b & 02 Aug 0000 to 03 Aug 0300 & SFC & & $\begin{array}{l}\text { Saharan dust, linearly organised storms } \\
\text { from Karlsruhe to the central Vosges } \\
\text { mountains }\end{array}$ \\
\hline
\end{tabular}


Table IV. (continued)

\begin{tabular}{|c|c|c|c|c|}
\hline IOP-14a & 06 Aug 1100 to 07 Aug 1800 & WFC & & $\begin{array}{l}\text { Isolated storms over the entire COPS domain } \\
\text { followed by a large area of elevated precipitation }\end{array}$ \\
\hline IOP-14b & 08 Aug, 0500-2100 & WFC & & $\begin{array}{l}\text { MCS in the north and large precipitation system } \\
\text { over Switzerland and SE of COPS domain }\end{array}$ \\
\hline IOP-14c & 09 Aug, 0700-1800 & WFC & & $\begin{array}{l}\text { Widespread precipitation system over COPS } \\
\text { domain }\end{array}$ \\
\hline IOP-15a & 12 Aug, 0400-2100 & $\mathrm{AMC}$ & & $\begin{array}{l}\text { Storm initiation over the eastern Black Forest } \\
\text { and Swabian Jura }\end{array}$ \\
\hline IOP-15b & 13 Aug, $0400-1800$ & WFC & & $\begin{array}{l}\text { Upper-level short-wave trough passes the COPS } \\
\text { area; CI in clear air ahead of and near the trough }\end{array}$ \\
\hline IOP-16 & 15 Aug 0830 to 16 Aug 0800 & SFC & & $\begin{array}{l}\text { Possibly rotating storm in far NW of COPS area; } \\
\text { elevated convection approaching from the west }\end{array}$ \\
\hline SOP-7 & 17 Aug, $0800-1600$ & & BAE & \\
\hline IOP-17a & 21 Aug 0700 to 22 Aug 0000 & WFC & & $\begin{array}{l}\text { Small showers over the northern Vosges } \\
\text { Mountains and in the Rhine valley }\end{array}$ \\
\hline IOP-17b & 22 Aug, $0700-1600$ & WFC & & $\begin{array}{l}\text { Towering cumulus developed over the northern } \\
\text { Black Forest }\end{array}$ \\
\hline IOP-18a & 24 Aug, $0500-1800$ & $\mathrm{AMC}$ & & $\begin{array}{l}\text { Towering cumulus formed over the mountains, } \\
\text { few very weak showers }\end{array}$ \\
\hline IOP-18b & 25 Aug, $0500-1800$ & $\mathrm{AMC}$ & & $\begin{array}{l}\text { Towering cumulus formed over the mountains } \\
\text { but no showers }\end{array}$ \\
\hline SOP-8 & 29 Aug, 0800-1700 & & BAE & \\
\hline
\end{tabular}

$* \mathrm{AMC}=$ Air-mass convection; $\mathrm{WFC}=$ weakly forced convection; $\mathrm{SFC}=$ strongly forced convection.

shown). In the whole COPS domain, average precipitation amounts were influenced by precipitation over the Alps and yielded approximately $135 \mathrm{~mm}$ in June, $133 \mathrm{~mm}$ in July, and $128 \mathrm{~mm}$, accumulating to an average of $396 \mathrm{~mm}$ during the COPS period.

The climatology of CI was investigated using DWD radar data for the time period 2000-2008 (Weckwerth et al., 2011). Figure 7 presents the climatology of the diurnal cycle of CI (grey bars) compared with an analysis of CI events during the COPS period (black bars). As expected, in summer, surface processes and CI events are strongly coupled in the COPS domain. During COPS, in spite of fewer events, the radar statistics was basically the same. The likelihood of CI was at a maximum around 1030 UTC, in good agreement with climatology and about five times higher than during night-time.

The RSS of the MSG satellite was also used for studying CI (Aoshima et al., 2008). Here, CI was defined as the observation of a certain threshold level in the $10.8 \mu \mathrm{m}$ brightness temperature. This analysis concentrated on the IOP days. A total of 94 CI events were found for which MSG data are available, i.e. for 30 days within 16 IOPs. In spite of the limited number of events, a diurnal cycle of CI was detected with a maximum at about 1300 UTC under all forcing conditions. In this one-hour period alone, $18 \%$ of all CIs took place. The likelihood of CI was slightly enhanced over the mountain ridges. Deviations between CI studies using radar and MSG are probably due to different sampling (only IOPs in case of MSG) and due to different detection methodologies.

The diurnal cycles of precipitation observed during each month and its average are presented in Figure $8(\mathrm{~b})$ ). During all months, the data indicate a diurnal cycle albeit with different amplitudes influenced by synoptic events. For instance, during August, the major amount of precipitation was produced by a cut-off low pressure system that resided for several days over France. On average, a diurnal cycle was found with a minimum of precipitation around 1400 UTC, followed by an increase in the evening. The diurnal maximum of CI occurred considerably earlier than the maximum in precipitation. This is likely due to the fact that the CI events were not weighted by the corresponding amount of precipitation. As we do not expect an enhancement of synoptically driven precipitation during night-time, we assume that the maximum is due to a longer lifetime and precipitation amount of convective cells and/or systems. The explanation of this mechanism will be an important subject of future studies.

The amounts of precipitation determined with the JDC dataset in the COPS region for the IOPs and SOPs are presented in Figure 8(a)). Significant amounts of precipitation not considered as an IOP were either due to large-scale stratiform precipitation, which was not the subject of COPS, or occurred after long IOPs, after which some recovery of instruments and staff was necessary. Otherwise, most of the precipitation events were covered including several severe weather events, e.g. during IOP $4 \mathrm{~b}$ (20 June) with heavy thunderstorms, IOPs $9 \mathrm{~b}$ and $9 \mathrm{c}$ with flooding events from UK down to Bavaria (19-20 July), and IOP 14 (6-9 August) with strong flooding events in Switzerland and southern Germany.

Investigation of several regional and large-scale parameters from ECMWF (re-)analysis data during the years 1979-2007 allowed us to put the meteorological conditions during COPS in the context of climatological conditions during the previous (almost) 30 years (Wernli et al., 2010). This analysis revealed that cyclones occurred with extraordinary frequency during summer 2007 over the British Isles, leading to a transport of relatively cool air masses from 

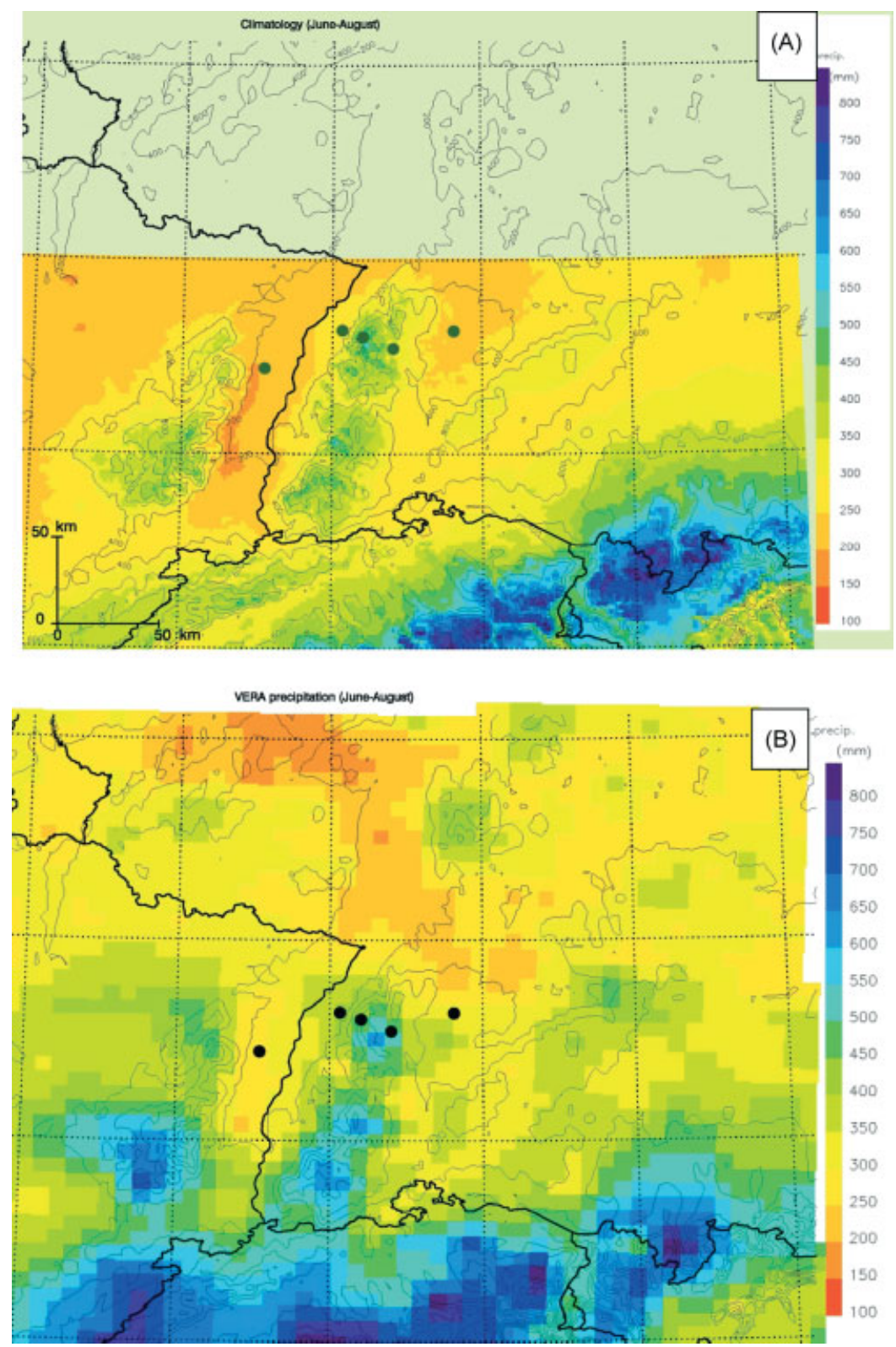

Figure 6. (a) $0.021^{\circ}$ resolution summer precipitation climatology in Europe from 1971 to 1990 (Frei and Schär, 1998). (b) Precipitation distribution during the COPS period in summer 2007 using $8 \mathrm{~km}$ VERA analysis of the JDC dataset. Thin and thick black lines show the orography and country borders, respectively.

the North Atlantic to France. The COPS region experienced fairly normal temperatures and enhanced humidity values in the low troposphere compared to climatology. Thermodynamic indices showed slightly increased potential instability. IOPs during COPS were performed mainly during warm and humid conditions, which is not surprising given the focus of COPS on precipitation events. The so-called COPS Atlas (Zimmer and Wernli, 2008) and MSG RSS analyses (Volkert, 2009) provide further details of the large-scale characteristics for all days during summer 2007.

\subsubsection{Land-surface exchange processes}

Extensive comparisons of the turbulence measurements showed that the magnitude of the latent and sensible heat flux was determined by the land use type rather than by the location of the site within the COPS region (Eigenmann et al., 2011). The process chain of soil moisture, surface fluxes, CBL conditions, and convection-related parameters over complex terrain are analysed by Hauck et al. (2011) and Kalthoff et al. (2011). The results were different for valley and mountain sites. Only in the Rhine valley, the ratios of sensible and latent heat to the net radiation, $H_{0} / Q_{0}$ and $E_{0} / Q_{0}$ respectively, revealed a dependence on soil moisture. $H_{0} / Q_{0}$ was lower and $E_{0} / Q_{0}$ was higher at higher soil moisture (Figure 9). In the Rhine valley, the mean diurnal increase of the equivalent potential temperature, $\theta_{\mathrm{e}}$, correlated with the energy supplied by the surface fluxes of heat and moisture. However, the correlation coefficient was low, indicating that the CBL conditions were also influenced to a great extent by advective processes. In the Black Forest, the evolution of $\theta_{\mathrm{e}}$ was nearly independent of the energy supply from the surface. In the valleys, the dependence of the ABL depth on the sensible heat flux was weak and non-existent at the Black Forest crest. 


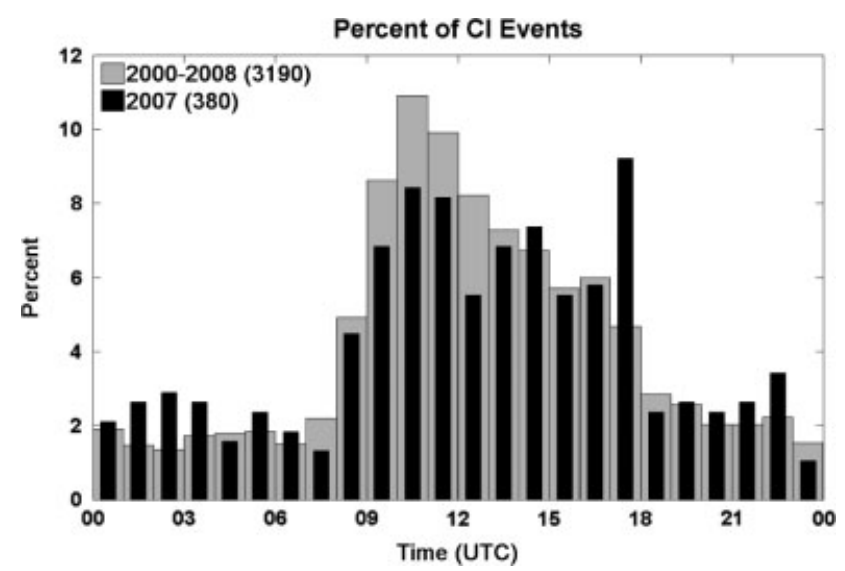

Figure 7. Diurnal cycle of CI in the COPS region. Grey bars show the climatology and black bars the COPS period (Weckwerth et al., 2011).
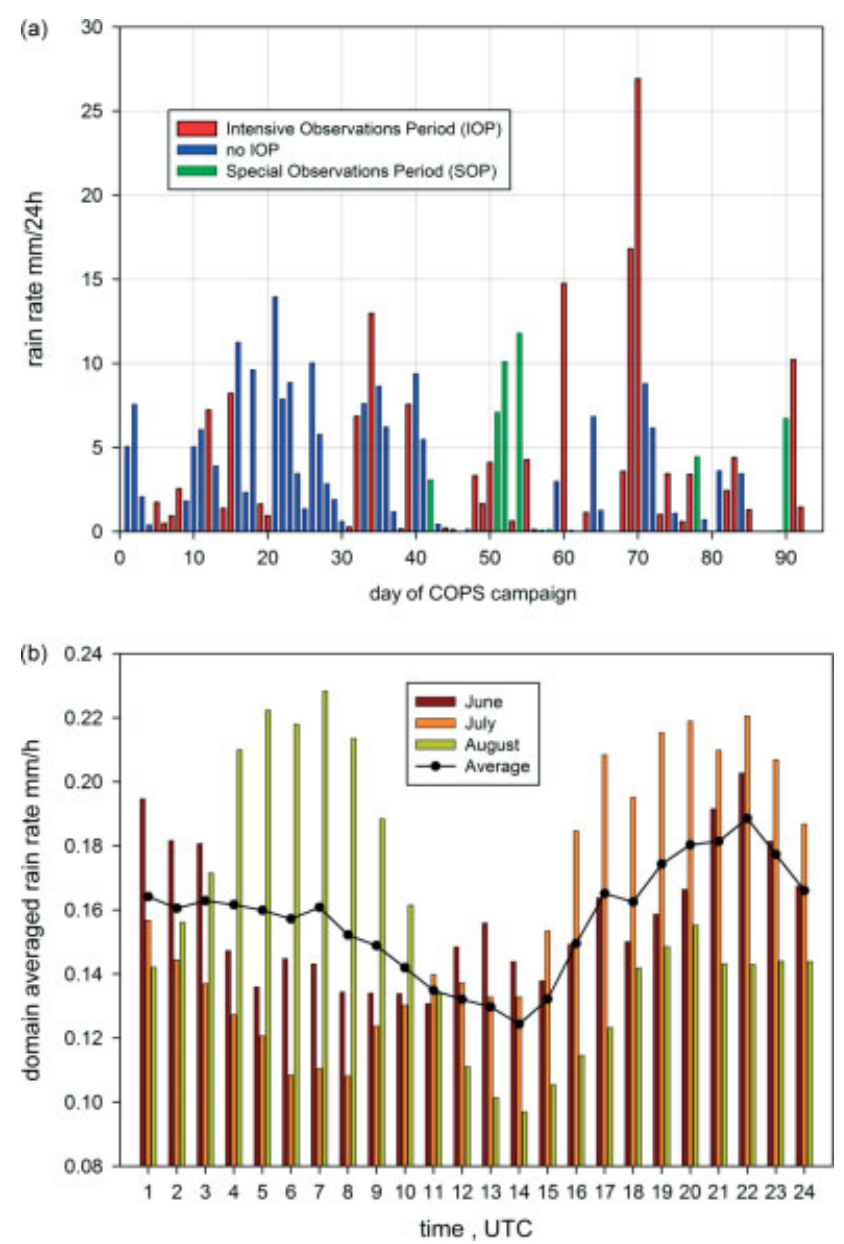

Figure 8. (a) Daily precipitation amounts during the COPS period. (b) Diurnal cycle of precipitation during the COPS period for each month and the average. The results were averaged over the COPS domain using the JDC dataset.

The convection indices in the whole COPS domain were found to depend on $\theta_{\mathrm{e}}$ in the CBL. CIN was positively correlated with the strength of the CBL-capping inversion and negatively with the CBL height: the higher the CBL, the lower the upper threshold of CIN. The frequency of low CIN was higher in the Black Forest than in the Rhine valley, which facilitates convection initiation over the mountain sites (e.g. Kalthoff et al., 2011; Behrendt et al., 2011).

\subsubsection{Thermally induced flow systems}

For studying CI, it is essential to observe the pre-convective, thermally induced flow and the resulting redistribution of humidity in the COPS low-mountain region. It is expected that the combination of dynamics and humidity leads to characteristic locations and structures of convergence zones as well as to specific 2D distributions of vertical stability of the atmosphere. As an example, the synergy of the mobile DOWs and the new UHOH WV DIAL system will be presented here.

During IOP 11b, which took place on 26 July 2007, the COPS domain was under the influence of a high pressure ridge which moved slightly east during the observation period. Consequently, deep convection did not take place. Nevertheless, several interesting mesoscale features were observed which are important for CI. Figure 10 presents an overlay of the orography, a three-channel RGB composite of MSG brightness temperature measurements, DOW LOS wind measurements at $100 \mathrm{~m}$ above ground, and also DOW LOS wind measurements and dual Doppler horizontal wind measurements in combination with POLDIRAD at $600 \mathrm{~m}$ above ground. The data are shown for 1100 UTC but they are available with a time resolution of $15 \mathrm{~min}$ from 1000-1600 UTC.

The LOS measurements indicate a mean flow from the southwest. Particularly striking are the line-like structures in the Rhine valley, which reveal the occurrence and orientation of horizontal convective rolls. At $1100 \mathrm{~m}$, the DOW range covered the supersites Achern and Hornisgrinde for combining the data with various remote-sensing systems, which were located at these sites. Figure 10(b) presents dual Doppler wind fields derived with DOW2 and POLDIRAD at $600 \mathrm{~m}$ above ground. The horizontal wind fields were derived with a spatial resolution of $\approx 500 \mathrm{~m}$ which cannot be reached with surface weather stations. These measurements were consistent with $8 \mathrm{~km}$ VERA analyses of the surface wind field showing southerly flow in the Rhine Valley in combination with thermally induced slope flows towards the low mountains. These convergent flow structures resulted in the development of shallow convection at the northern tip of the Vosges mountains, which are visible in the satellite image.

Figure 11 presents the WV profiles measured with the IPM DIAL system over supersite $H$. The results confirm the outstanding resolution of DIAL measurements in the lower troposphere with resolutions of $1 \mathrm{~s}$ and $15 \mathrm{~m}$, respectively (Wulfmeyer and Walther, 2001a,b; Behrendt et al., 2009). Turbulent processes in the CBL are resolved which were capped by a strong inversion layer. In the free troposphere, a tremendous vertical variability of $\mathrm{WV}$ was observed. The $\mathrm{WV}$ variance was mainly due to turbulence, but there are two distinct minima at 1344 and 1355 UTC. First comparisons with the DOW data indicated that these may be due to the presence of horizontal rolls advected over the supersite. In this case, the CBL WV variability of about $1 \mathrm{~g} \mathrm{~m}^{-3}$ was partly due to turbulence and partly due to mesoscale coherence caused by convective rolls, which is consistent with previous observations (Weckwerth et al., 1996).

Consequently, the combined information on dynamics by the DOWs and humidity by lidar gives unique insight into the impact of meso-gamma scale processes on the variability of humidity in the ABL. Further applications of DOW, DIAL, and surface network synergy for ABL process studies 
(a)
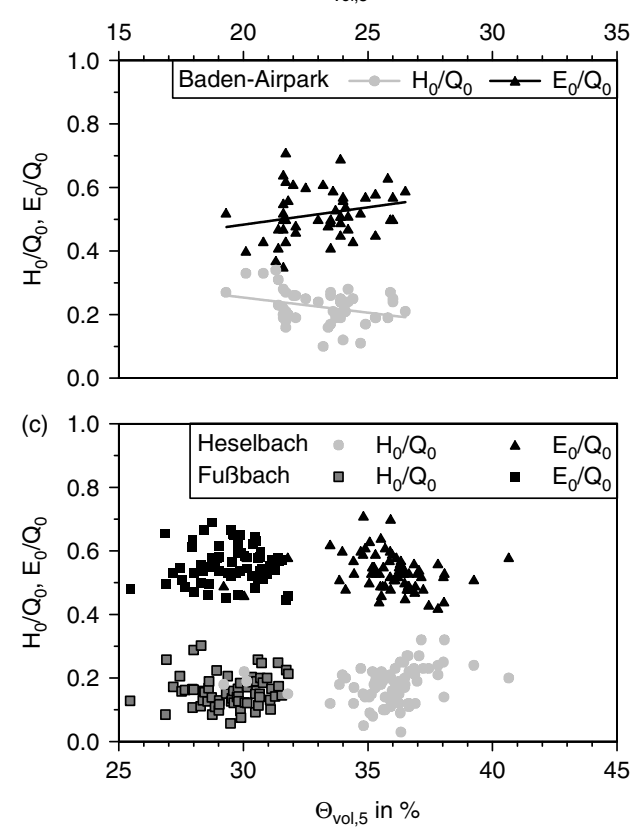

(b)

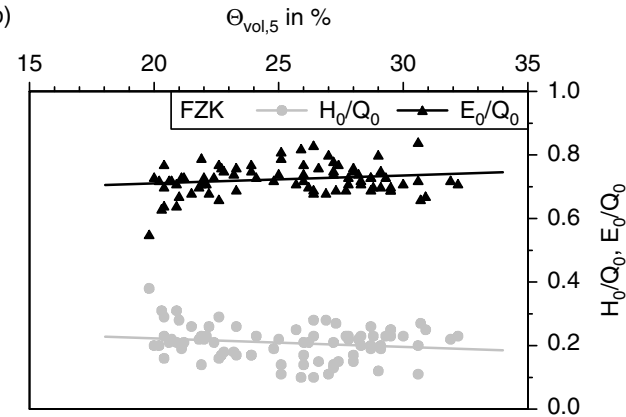

(d)

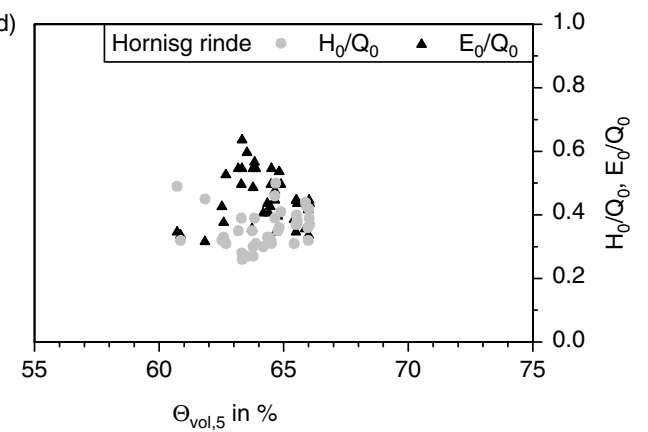

Figure 9. Ratios of sensible heat flux to net radiation, $H_{0} / Q_{0}$, and latent heat flux to net radiation, $E_{0} / Q_{0}$, as a function of soil moisture at $5 \mathrm{~cm}$ depth, $\Theta_{\mathrm{vol}, 5}$, at five different sites, using data from the entire COPS period.

are found in Behrendt et al. (2011), Bennett et al. (2011), and Corsmeier et al. (2011).

\subsubsection{Air mass convection during IOP8b}

One of the COPS science hypotheses was that accurate modelling of the orographic controls of convection is essential and only possible with advanced mesoscale models featuring a resolution of a few kilometres. An outstanding case for this issue was COPS IOP $8 \mathrm{~b}$, where local ABL processes related to orography were the dominant processes for CI.

During IOP 8b on 15 July 2007, a single convective cell developed east of the Black Forest crest, although CAPE was only moderate and CIN was high. On that day, the COPS area was located in the transition zone between an eastern European ridge, stretching from the Mediterranean Sea to Poland and a high-amplitude eastern Atlantic trough. GFS analyses showed that only little advection of PV in the upper troposphere and warm air in the lower troposphere prevailed throughout the whole day (Kalthoff et al., 2009). As a consequence, the large-scale forcing was of minor importance. Low cloud conditions allowed for high insolation, resulting in a high $\mathrm{ABL}$ temperature. In combination with the orography, this favoured the development of local circulation systems over the mountain range.

COPS observations were particularly dense and permitted the study of the interaction of mesoscale and thermally induced flows in unprecedented detail (Behrendt et al., 2011). It was found that thermally driven circulation systems formed a convergence zone along the mountain crest of the Black Forest which was amplified by a mesoscale convergence zone, so that strong updraughts were observed above the mountains (Kalthoff et al., 2009, Behrendt et al., 2011). The values of CAPE and CIN were modulated by a moist tongue stretching southwards and reaching the northern part of the Black Forest. About $15 \mathrm{~min}$ after the convergence zone had passed the Black Forest crest, first clouds developed east of it. While moving further eastwards, the convergence zone intensified and became visible as a north-south oriented cloud line in the satellite images. The main thunderstorm, however, was initiated in the transition zone from the northern to southern Black Forest east of the Kinzig valley, likely due to an amplification of convergence by a strong and deep valley flow. The strong spatial correlation of the convergence with subsequent cloud formation strongly suggests that lifting along this convergence line was the key trigger mechanism of the observed convective cell on that day. A detailed observational study was performed by Behrendt et al. (2011) and further model studies of this fundamental case are presented by Barthlott et al. (2010, 2011), and Richard et al. (2011).

\subsubsection{Orographically induced modification of fronts and prefrontal convergence lines}

IOP 9 consisted of a three-day observation period (IOP 9a-c) from 18 to 20 July 2007 where all COPS and ETReC2007 resources were exploited and coordinated most closely. The development of a frontal zone with enhanced CI and subsequent storms governed by multiple-scale interaction processes, oriented from southwest to northeast over the COPS region, was investigated in great detail. Cyclogenesis over France between 19 and 20 July 2007 was predicted consistently by the global models of ECMWF and GFS. However, LAMs predicted different developments and tracks of MCSs associated with the cyclogenesis as well as different precipitation patterns propagating northeastwards.

Overlays of COPS observations of IOP 9c (20 July 2007) are presented in Figure 12. Ahead of the weak cold front related to the cyclone over northern France, the outflow of an embedded MCS generated a gust front passing the Vosges and Black Forest mountains in the morning. The gust front interaction with a thermally driven convergence line over 

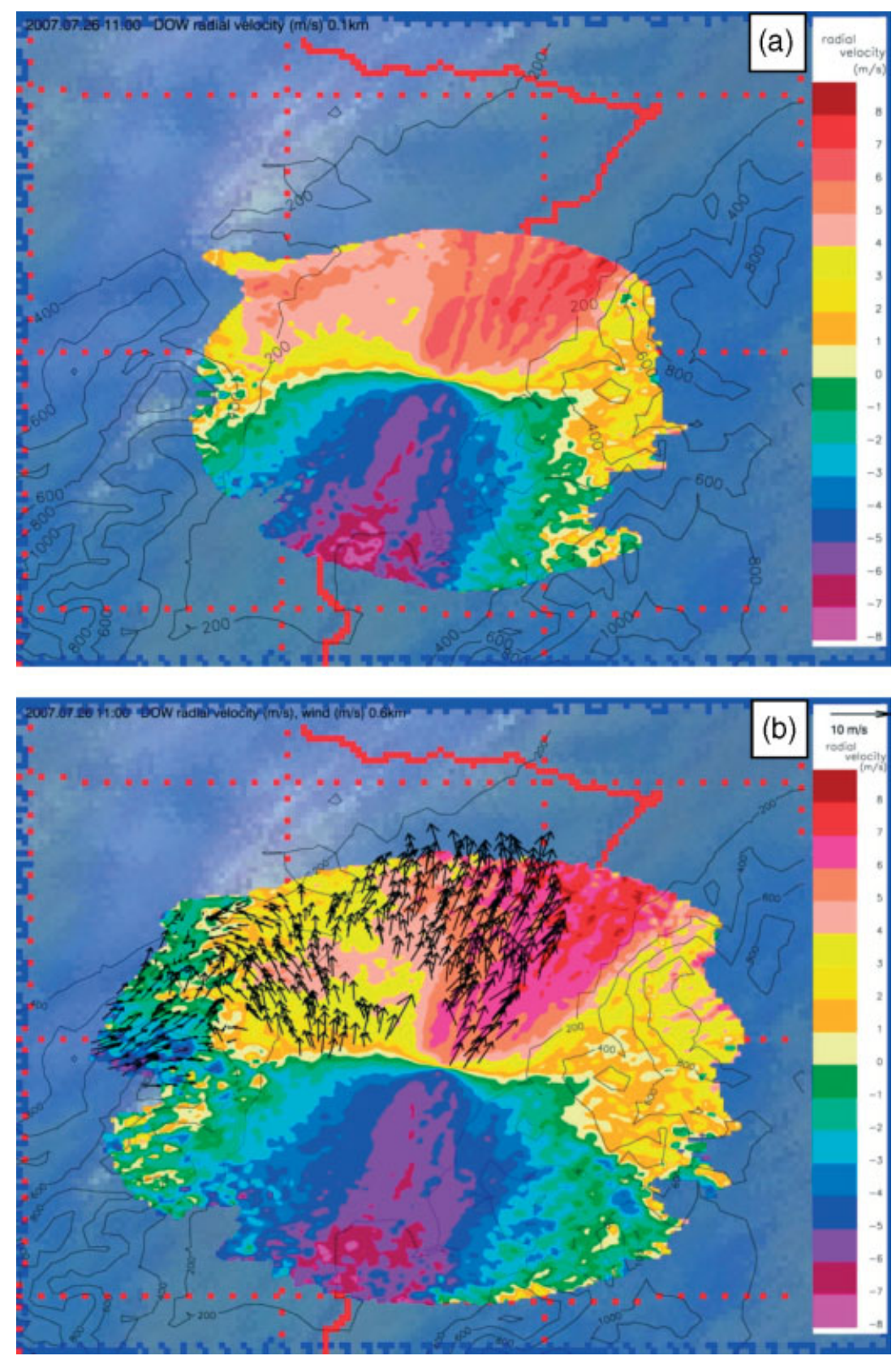

Figure 10. (a) MSG three channel composite (red: $0.6 \mu \mathrm{m}$ (Ch1), green: high-resolution visible (Ch12), blue: IR10.8 $\mu \mathrm{m}$ (Ch9) inverted, resulting in green to grey shading of land surface and clouds, respectively), and DOW LOS wind measurement at $100 \mathrm{~m}$ above ground at 1100 UTC on 26 July 2007. The measurement shows mesoscale flow from the southwest in combination with horizontal roll vortices in the Rhine Valley. (b) The same observations, but $600 \mathrm{~m}$ above ground and with the addition of dual Doppler retrieval of the wind field (arrows) by combined DOW and POLDIRAD LOS measurements. In both, the thin grey contours show the orography.

the Black Forest produced a squall line with severe thunderstorm activity in the eastern COPS area. The structure and behaviour of the squall line looked similar to an event which took place during IOP 9 one day earlier. However, this time, deep convection was significantly stronger and took place over the Black Forest and the Swabian Jura in the core of the COPS domain.

A scan of the convective cells triggered over the crest of the Black Forest using POLDIRAD is presented in Figure 13 and includes a retrieval of microphysical properties. Two convective cells located at distances of 65 and $100 \mathrm{~km}$ are visible at 1059 UTC. These were triggered at 1000 UTC above supersite $\mathrm{H}$ ahead of the frontal system by interaction of the easterly propagating MCS gust front and the convergence line in front of it (Corsmeier et al., 2011).
Due to rapid development, the cells reached the tropopause within $30 \mathrm{~min}$. The interaction modified the structure of the gust front-convergence line system into a squall line with severe thunderstorms. After the merging of the squall line with the northern cold front associated with the low over the English Channel, the whole system developed into a bowlike structure ranging from the Netherlands to southern Germany. The deep convective cells propagated with their related precipitation pattern several $100 \mathrm{~km}$ downstream (Figure 12). Further outflow boundaries caused secondary convection to be triggered in Bavaria later in the afternoon.

This case demonstrates (i) the importance of scale interaction for convection-driving processes and (ii) the existence of a two-way scale interaction from large to small scales and vice versa. Extensive D-PHASE model 


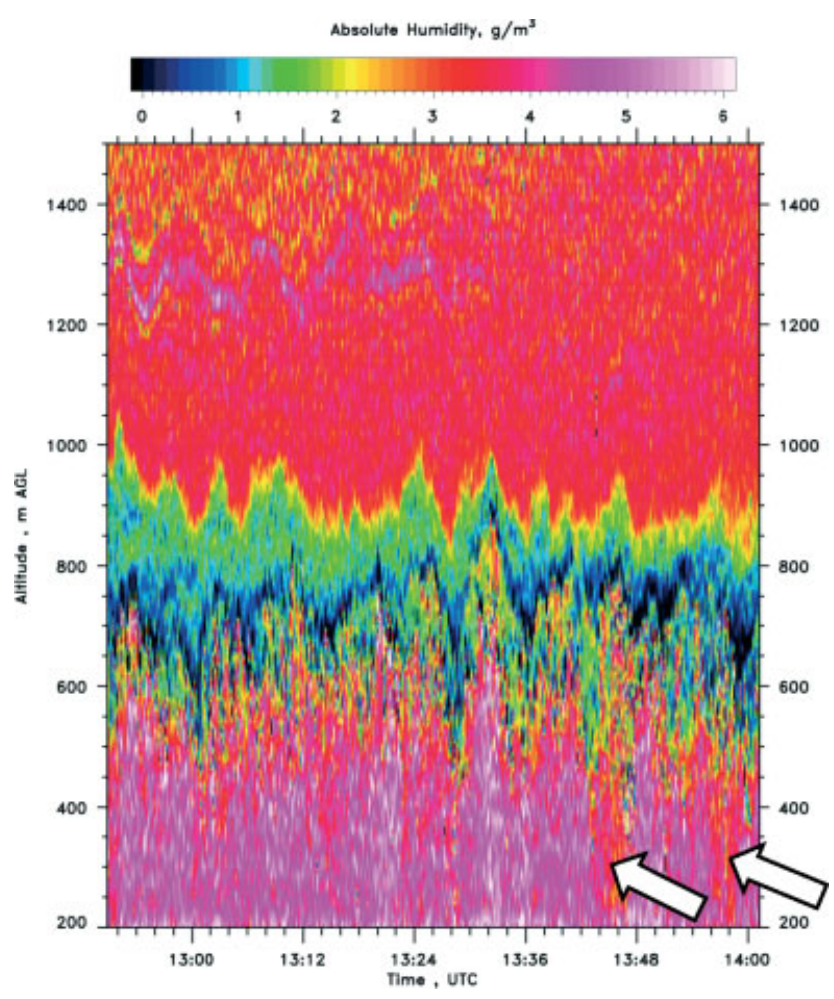

Figure 11. Vertical profiles of absolute humidity measurement from the UHOH WV DIAL during IOP $11 \mathrm{~b}$, on 26 July 2007. The resolution of the data is $15 \mathrm{~m}$ and $1 \mathrm{~s}$. The arrows indicate fluctuations in the humidity field which may due to horizontal rolls.

comparisons have been initiated in order to study this case. Preliminary results show that nearly all D-PHASE mesoscale models initialized at 0000 UTC missed the initiation of convection related to the squall line on the lee side of the Black Forest. Most models did not produce the southern part of the squall line, sub-synoptic in dimension, upstream of the Vosges mountains. Furthermore, almost all models predicted a too slow propagation speed for the squall line. Figure 14 presents an example. Figure 14(a) shows the overlay of the surface wind field as well as the MSG and the radar composite. Figures $14(\mathrm{a})$ and (b) present the corresponding fields initialized at 0000 UTC and valid at 0800 UTC of the MeteoSwiss COSMO2 and COSMO7 models, respectively. Already at this time, the squall line and the location of the frontal system were not modelled correctly. The inadequate simulation of the prefrontal convergence line may be due to underestimated cooling of the convective outflow (which may be related to an incorrect autoconversion rate), and/or the improper simulation of the initial MCS gust front and its interaction with the convergence line.

This IOP provides an excellent case for studying the interaction of large-scale and small-scale processes leading to deep convection, its organization, and its interaction with orography and for studying the performance of mesoscale models (Corsmeier et al., 2011; Smith et al., 2011, pers. comm.; Schwitalla et al., 2011).

\subsubsection{Aerosol-cloud-precipitation microphysics}

A prerequisite for understanding the interaction between aerosols, clouds and precipitation is accurate information on microphysical cloud properties. The LWP is extremely important for comparisons with cloud parametrizations, yet the typical uncertainty in the LWP retrieved from 'traditional' microwave radiometers is about $25 \mathrm{~g} \mathrm{~m}^{-2}$ (e.g. Turner et al., 2007). The sensitivity to small amounts of liquid water is much larger at higher frequencies, and thus incorporating measurements at 90 or $150 \mathrm{GHz}$ into the LWP retrievals would reduce the random errors by a factor of $2-3$ (Crewell and Löhnert, 2003). Evaluation of microwave absorption models resulted in improvements for both precipitable WV and LWP retrievals with respect to the WV absorption in all of these models (Turner et al., 2009). The LWP data are now being utilized to better characterise the accuracy of the liquid water content profile (Ebell et al., 2009). These cloud bulk microphysical properties are also being used to investigate the cloud radiative forcing over supersite $\mathrm{M}$ for the full nine-month deployment of the AMF (Ebell et al., 2011).

One goal of COPS is to determine the properties of aerosol in the convective cloud inflow and to understand the formation and growth of ice and precipitation in the clouds as influenced by the aerosols. For example, the high concentration of ice particles observed in clouds on 11 July 2007 was likely due to the secondary production of ice by splintering during riming (the so-called Hallett-Mossop process). However, conditions do not appear to have been favourable for this process to be active in the 15 July 2007 cloud because there was a large concentration of relatively small cloud particles and few graupel particles. Interestingly, there was a high fraction of highly oxidized organic mass observed by the time-of-flight Aerosol Mass Spectrometer at Hornisgrinde. Microphysical modelling results predicted the existence of high concentration of small ice particles that might have been generated by nucleation on biogenic ice nuclei, which are believed to be more efficient. Unfortunately, the cloud particles were too small and too numerous for the instruments to confirm or refute this prediction.

Several studies are investigating the interaction between aerosol particles and precipitation either via radiation or microphysical effects. During IOP $8 \mathrm{~b}$, strong boundarylayer updraughts were measured by the BAE 146 aircraft near the Murg valley associated with high concentrations of aerosols and $\mathrm{WV}$ as the convergence line passed over the valley. The aircraft measurements also showed that the air in the southern domain around the Kinzig valley was much less polluted than in the northern area. The results from a model sensitivity test suggest that aerosols could have an impact on the dynamics and depth of the cloud via a cooling effect and particle loading.

Junkermann et al. (2011) found a significant source of ultrafine particles in Karlsruhe, which could affect precipitation on a regional scale downwind of Karlsruhe after growth to cloud condensation nuclei sizes. Another exciting study is dealing with the radiative effect of Saharan dust outbreaks during IOP 13 (1-2 August 2007). Chaboureau et al. (2011) demonstrated that a Saharan dust layer can lead to an increase of CAPE and thus to higher precipitation amounts. Simulations with a mesoscale dust transport model are in better agreement with observations than if this effect were disregarded.

\subsubsection{Data assimilation}

DA within mesoscale models is a very active research area that has been strongly profiting from COPS activities. DA efforts include the application and investigation of different 

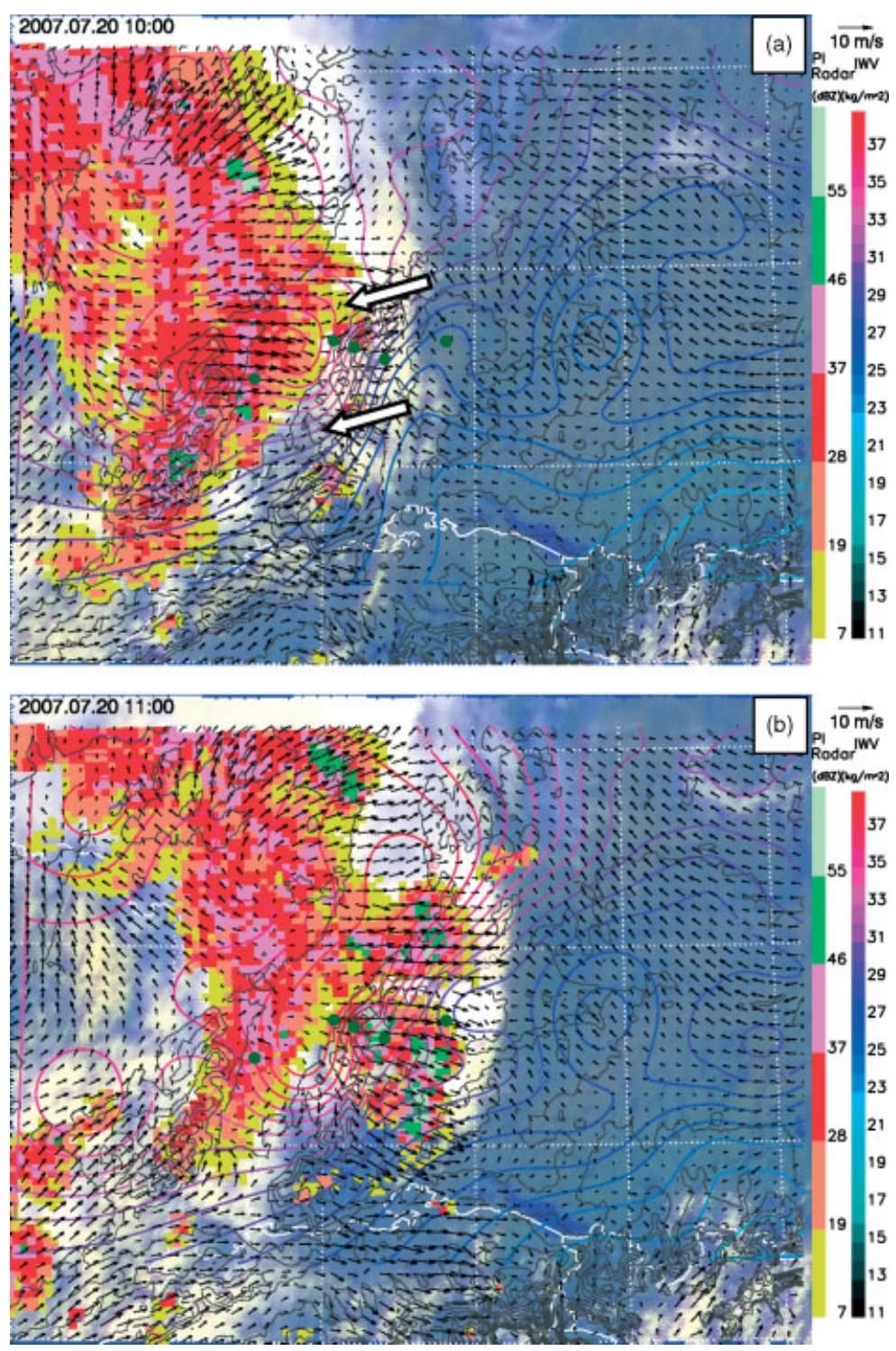

Figure 12. Overlay of data showing the passage of a prefrontal squall line on 20 July 2007. Orography (thin black contour lines), three-channel MSG composite (green to gray shading), IWV from GPS (coloured contour lines), the European radar composite (color contour plot), and 8-km VERA surface wind arrows are shown at (a) 0955 UTC and (b) 1055 UTC. Two deep convective cells initiated in the Black Forest are marked by white arrows. Some outflow boundaries leading to secondary $\mathrm{CI}$ are detected in the wind field before any cloud is observed.

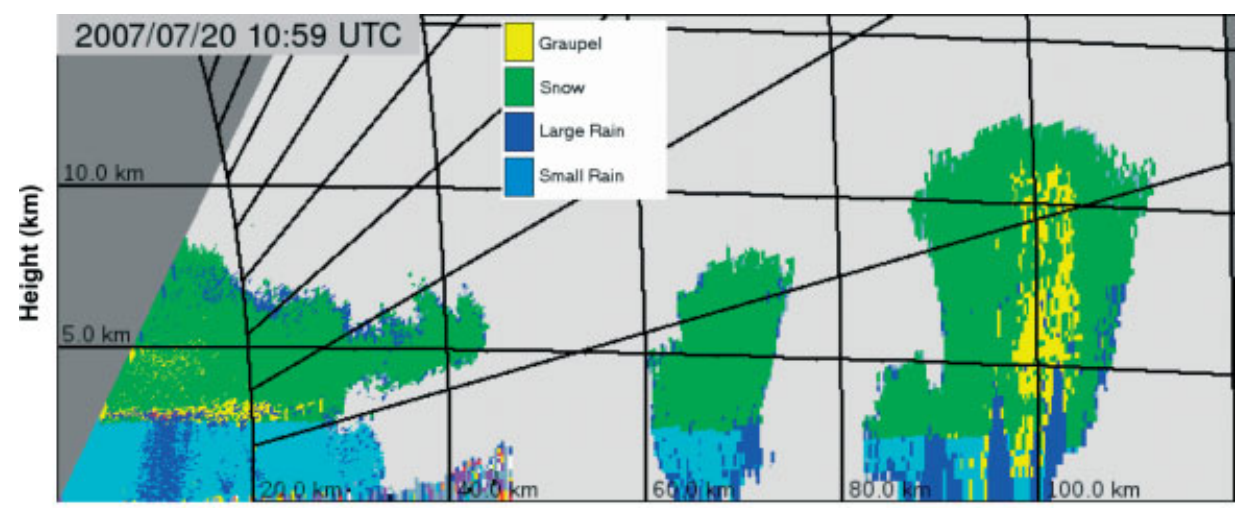

Distance from POLDIRAD $(\mathbf{k m})$

Figure 13. RHI scan of POLDIRAD along the transsect of COPS supersites (azimuth angle $109.2^{\circ}$ ) in the northern Black Forest during IOP9c, 20 July 2007. Supersites R, H, and M were located at distances of 35, 45 and $60 \mathrm{~km}$, respectively. Hydrometeor classification using polarisation is possible and was applied for a range up to about $100 \mathrm{~km}$. 


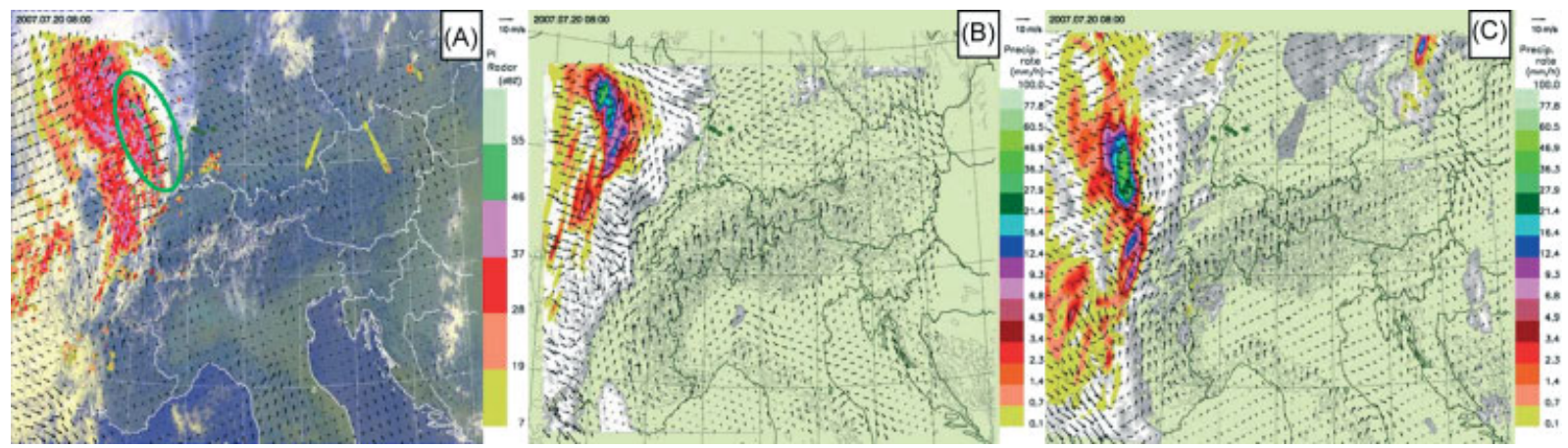

Figure 14. (a) is as Figure 12, but over the larger D-PHASE domain. (b) and (c) show corresponding simulations from the MeteoSwiss COSMO2 model and its driving model COSMO7, respectively, with an initial time of 0000 UTC. Neither model reproduced the squall line and its strong outflow boundary, which extended down to northern Switzerland and eastern France, indicated by the green ellipse in (a).

methodologies such as nudging, 3D variational analysis $(3 \mathrm{D}$ Var), 4D-Var, and the EnKF. Nudging of radar data has been performed at ARPA SIMC in Bologna and the UB. Nudging of standard, GPS, and radar data is being applied at DWD, e.g. in connection with new COPS reanalyses. However, surface data have also been assimilated. For instance, a retrospective EnKF was applied for the assimilation of streamflow data for improving initial soil moisture fields (Warrach-Sagi and Wulfmeyer, 2010).

Particular progress has been achieved in the application of modern variational DA techniques such as 3D-Var and 4D-Var using European GPS ZTD and STD data with density increased by the COPS network as well as radar and lidar data. Météo-France successfully assimilated GPS ZTD using the 3D-Var RUC of the AROME model and demonstrated a positive impact on short-term QPF (Yan et al., 2009). Previously, the first mesoscale lidar DA research was performed using MM5 4D-Var (Wulfmeyer et al., 2006; Grzeschik et al., 2008), which showed a positive impact on QPF during the IHOP_2002 campaign. This research was intensified during COPS using a large suite of airborne lidar data assimilated in the AROME 3D-Var RUC. A positive impact on QPF lasting up to $12 \mathrm{~h}$ was also found there, in most cases (Richard et al., 2010).

For the first time, to our knowledge, IPM performed quasi-operational forecasts using 4D-Var of GPS STD data during the DOP from June to November 2007 and demonstrated, not only by case-studies but also with monthly statistics, a positive impact of GPS STD on short-range QPF (Bauer et al., 2009a,b, 2010). An IOP $9 \mathrm{c}$ case-study also confirmed a slightly positive impact of GPS ZTD DA in the WRF 3D-Var system even without a RUC (Schwitalla et al., 2011). Further studies using GPS ZTD and STD data as well as Doppler radar wind data are ongoing using the 3D-Var of the Météo-France AROME model and a WRF 3D-Var RUC currently being prepared at IPM.

DA was not only used for optimizing initial fields but also for studies of model physics. For instance, $4 \mathrm{D}-$ Var reanalyses in a $3 \mathrm{D}$ data assimilation window demonstrated a superior performance of the Grell over the Kuo convection parametrization (Zus et al., 2008). These successful applications and the significant positive impact of GPS DA on short-range QPF using advanced variational techniques on the meso-gamma scale are very encouraging for the operational use of these datasets.

\subsubsection{Model verification and predictability}

By coordinating COPS with the WWRP FDP D-PHASE (Rotach et al., 2009a,b), a huge multi-model ensemble of weather forecast models was operated in the COPS domain. This is an excellent opportunity to compare skill scores of state-of-the art deterministic models, ensemble forecast systems, and specially designed multi-model ensembles after calibration. Within D-PHASE, advanced verification skill scores such as fuzzy verification were applied over Switzerland (Ament et al., 2010; Weusthoff et al., 2010) demonstrating superior performance of the new generation of convection-permitting models over the models with convection parametrization. In the COPS and D-PHASE domains, the new JDC dataset is being used to take advantage of the high station density (Figure 2). Fuzzy verification has been applied to a majority of the D-PHASE models to compare the performance of models with and without convection parametrization. Furthermore, the diurnal cycle and the spatial distribution of precipitation are being verified.

Figure 15 presents a first result, the difference between cumulative precipitation simulated using the COSMO7 and COSMO-EU models (Figures 15(a) and (c)) with convection parametrization minus observations over the whole COPS period. The windward/lee effect is easily visible in the models with convection parametrization leading to large systematic errors in the Black Forest region, the Vosges mountains, and the forelands of the Alps. The systematic error on the windward side of the low mountains is $\approx 100 \%$. This effect is virtually eliminated in the convection-permitting models (Figures 15(b) and (d)). Similar structures are also found in global and regional climate simulations (Kleinn et al., 2005; Feldmann et al., 2008; Chu et al., 2010), casting doubt on spatial and trend analyses of regional and global climate model projections and their hydrological applications in these areas.

Skill scores also need to be studied on short time-scales capturing the diurnal cycle of precipitation. Otherwise, systematic errors like spin-up problems are masked by integration over longer time periods. First results confirm improvements of the simulation of the diurnal cycle of precipitation using convection-permitting models. An overview of the status of the extensive verification efforts is found in Bauer et al. (2011).

The predictability of convective precipitation in a lowmountain region is being studied by Barthlott et al. (2011) using a convection-permitting multi-model ensemble. An 
COSM07-VERA precipitation 06-18 UTC (COPS period)

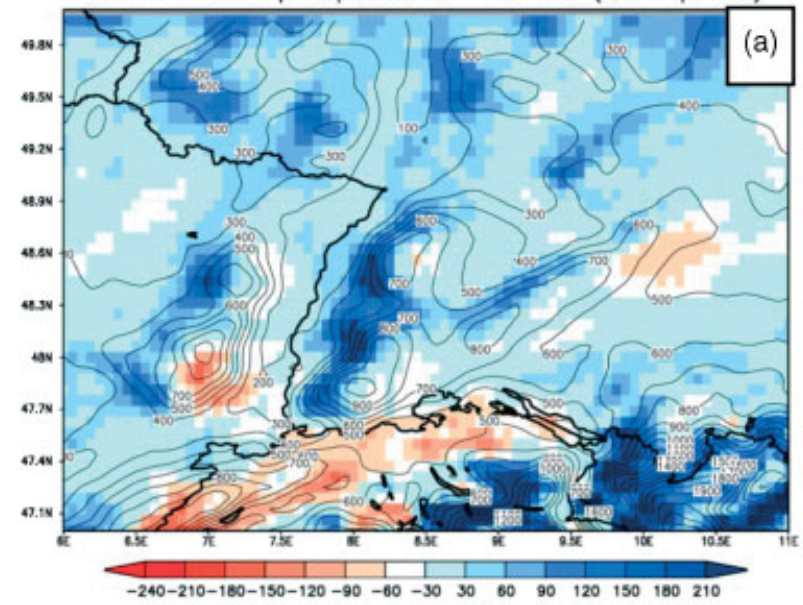

COSMOEU-VERA precipitation 06-18 UTC (COPS period)

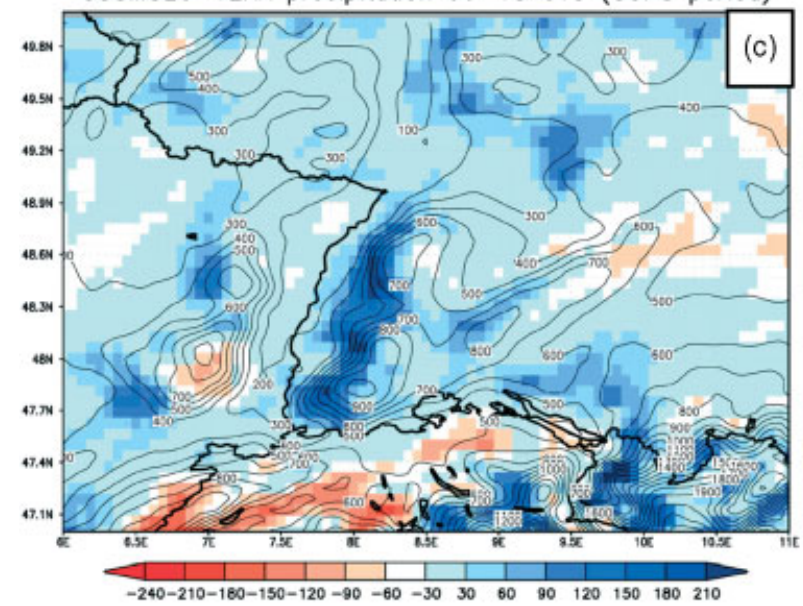

COSM02-VERA precipitation 06-18 UTC (COPS period)

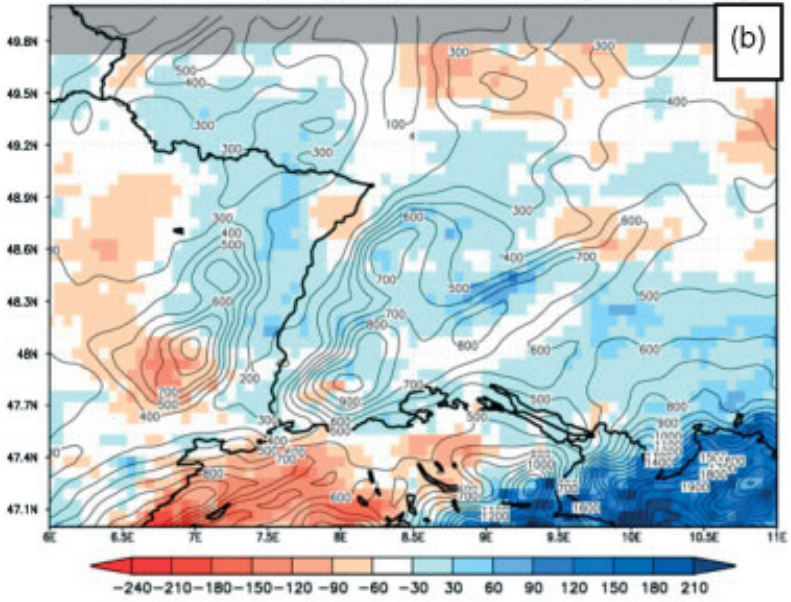

COSMODE-VERA precipitotion 06-18 UTC (COPS period)

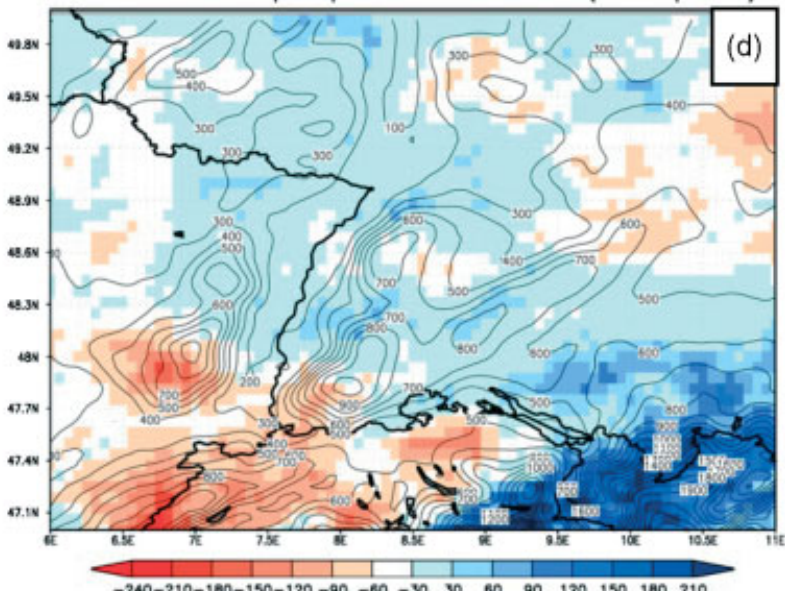

Figure 15. Difference (mm) between simulated and observed (VERA) accumulated precipitation from 0600 to 1800 UTC for the whole COPS period (from 0000 UTC initial times). (a) and (c) use Meteo Swiss COSMO7 and DWD COSMO-EU models with 7-km grid resolution and convection parametrization. (b) and (d) use the corresponding convection-permitting models COSMO2 and COSMO-DE, respectively.

ensemble of the UK Met Office Unified Model was also applied to study IOP $8 \mathrm{~b}$. These results indicate that orography can increase the predictability of CI, as long as characteristic thermodynamically induced flows as main forcing mechanisms are simulated correctly in the models.

Keil and Craig (2009) performed predictability analyses by generating an ensemble of COSMO-DE runs driven by different initial fields of the ECMWF EPS. Current research is focusing on regime-dependent forecast uncertainties of convective precipitation using selected COPS time periods. Furthermore, subsets of COPS data are used for best member selection for convective-scale ensembles. Further studies based on the D-PHASE ensemble include extensive process, verification, and predictability studies also using probabilistic skill scores (Dorninger and Gorgas, 2010) as well as ensemble calibration and studies of predictive skill scores based on Bayesian statistics.

\section{Summary and outlook}

In this publication, an overview of the performance and the first scientific results of the WWRP RDP COPS are presented. COPS was the first international field campaign in low-mountain areas addressing key systematic errors in QPF such as the windward-lee effect and errors in the diurnal cycle of precipitation. These errors do not only appear in NWP but also in global and regional climate models, accounting for corresponding research as a key overlapping issue of weather and climate research.

In order to foster PrQPF research, comprehensive datasets derived from observations and model simulations were produced. In the COPS and D-PHASE domains, simulations of a huge multi-model ensemble consisting of six ensemble prediction systems, eleven models with convection parametrization, and eleven convection-permitting models are available in a common GRIB1 data format. This considerably simplifies the process, verification, and predictability studies and can serve as a guiding example for coordinated multi-model simulations such as the TIGGELAM project (http//:www.smr.arpa.emr.it/tiggelam).

New networks were set up or the density was increased for soil moisture, land-surface exchange, surface variable, and atmospheric humidity measurements. A new highresolution surface dataset, the so-called JDC dataset, was collected and harmonized over central Europe during 2007. The data have been processed for providing $8 \mathrm{~km}$ gridded precipitation data with integration times of $1,3,6,12$, and $24 \mathrm{~h}$. As this effort consumed significant resources, WWRP recommends that EUMETNET fosters the development of Europe-wide, harmonised, quality-controlled datasets of surface stations, GPS, and radar. This would simplify the 
applications of these crucial datasets for the upcoming WWRP projects in Europe such as the HyMeX.

The observational highlights include what is, to our knowledge, the largest combination of multi-wavelength passive and active remote-sensing systems ever deployed during a field campaign. Fourteen lidar systems (eleven ground-based, three airborne), three cloud radars, ten precipitation radars, eight MWRs, one FTIR, and five sodars were operated in synergy with in situ measurements mainly at five supersites along a west-east transsect through the COPS domain. Some of these instruments were successfully demonstrated for the first time, e.g. the airborne Doppler lidar and WV DIAL combination of DLR Oberpfaffenhofen (Wirth et al., 2009) and the ground-based, scanning WV DIAL of UHOH (Behrendt et al., 2009).

Ten aircraft with different special sensors were operated according to a sophisticated pattern of coordination with each other and with ground-based sensors in a region with high commercial aircraft density. The combination of sensors permitted the observation of atmospheric variables and aerosol-cloud microphysics in a larger domain. This allowed the closing of gaps between the supersites and for upstream observations in connection with ETReC2007. In total, 2700 soundings are available, $11000 \mathrm{~h}$ of lidar data, $400 \mathrm{~h}$ of aircraft data and 10000 model runs with $5 \times 10^{7}$ model fields and plots in the COPS domain. Including passive and active remote-sensing systems, most of the data are provided in harmonised formats and were processed with the same retrieval algorithms. Data of the AMF collected during nine months of continuous operation are available from the ARM data archive. COPS measurements were supported by the EUMETSAT MSG RSS. The success of the RSS operation led to the operational RSS of MSG-8 which commenced on 13 May 2008, after consideration of the COPS results.

Several research highlights were presented. These include a thorough analysis of the spatial and temporal distribution of precipitation during the COPS observation period. The COPS summer was wetter than climatology but the spatial distributions and trends, e.g. the decrease of summertime precipitation from June to August in the low-mountain range, were similar. Diurnal cycles of CI and precipitation were found to peak at 1100 UTC and 2200 UTC, respectively. The investigation and understanding of this phase delay is an important subject of future research.

A key research aspect is the understanding of the process chain leading to CI, clouds, and precipitation using COPS observations and modelling studies with a focus on convection-permitting models. Observations demonstrate that sensible and latent heat fluxes were barely dependent on soil moisture, so that these fluxes are mainly controlled by vegetation. This is an important result, as most mesoscale models show a strong dependence of precipitation on soil moisture in this region. The COPS measurements indicate that this model behaviour may be incorrect and is likely due to an inadequate description of land-surface exchange processes.

Mesoscale and thermodynamically induced flow systems were studied in unprecedented detail. The development and structure of convergence zones due to flow splitting, channelling and thermally induced flows were investigated as well as their modulation of CAPE and CIN. Within all forcing conditions, from airmass convection during IOP $8 b$ to strongly-forced conditions during IOP 9c, orographically induced flows had a decisive role on CI as well as on the precipitation distributions within and downstream of the COPS domain. Convection-permitting models showed a promising performance in the simulation of these events. Models with parametrizations of deep convection misplaced convergence lines and thus the location of deep convection, which led to the windward-lee effect. However, the detailed structure of orographic flows and their interaction with vertical stability in convergence zones are neither fully understood nor well reproduced by simulations. This is the subject of extensive research activities, which will be extended to sensitivity analyses of QPF on aerosol-cloud-precipitation microphysics.

A considerable number of data assimilation studies were initiated within COPS. Assimilation of GPS ZTD and STD as well as WV lidar data in combination with 3D- and 4D-Var demonstrated a promising positive impact on short-range PrQPF lasting up to $12 \mathrm{~h}$. Further studies are ongoing based on the combined assimilation of surface, GPS, and radar data, using RUCs of convection-permitting 3D-Var, 4D-Var and/or the EnKF.

The predictive QPF skill of a subset of the DPHASE ensemble demonstrated superior performance of convection-permitting models in the COPS region. There are strong indications that orographically induced forcing can increase the predictability of CI and precipitation in low-mountain regions but the limitations are currently unclear. In order to investigate this, the next step is the development of advanced, calibrated ensembles of convection-permitting models. Accompanied by extensive verification studies based on the COPS observations, these ensembles will permit in-depth research on the role of orography for PrQPF and dependence on forecast range and interaction of forcing conditions. Within the WWRP Strategic Plan 2009-2017 (WMO, 2009b), a new IMRE has been proposed by the WWRP WG on MWFR to provide the required platform for joint coordinated future process and predictability studies on a European scale (http//:www.wmo.int/pages/prog/arep/wwrp/new/ mesoscale_new.html). It can be expected that the COPS dataset will make a significant contribution to one of the paramount issues of weather and climate research: the exploration of the bounds of predictability in low-mountain regions.

\section{Acknowledgements}

The COPS field phase received strong support by the DFG via the Priority Programme 1167 (grants WU 356/4-1, 4-2, 4-3, 9-1), the US ARM Programme, ANR (grant ANR-06BLAN-0018-04: COPS/France), CNRS/INSU (LEFE/IDAO program), CNES and Météo-France, the UK NERC, the Austrian Science Foundation (FWF) (grants P 19658-N10, $\mathrm{P}$ 20925-N10) and all institutions with which the coauthors are affiliated. The authors are grateful to INSU for the loan of the 'French' GPS station. EUFAR provided aircraft support, and EUMETSAT the MSG RSS. COPS was supported by WWRP by the endorsement as an RDP. COPS received substantial contributions of DWD, Météo-France, and MeteoSwiss as well as ECMWF. Mission planning greatly profited from the forecasting skills of Jerôme Pauthe, Julien Billault-Chaumartin, and Cédric Hertzog (MétéoFrance with the Synergie platform), Marco Stoll (MeteoSwiss 
with the NINJO platform) as well as Pieter Groenemeijer, Christian Ehmann, Johannes Dahl, and Bernhard Mühr.

EUMETNET and EUCOS provided additional targeting measurements within ETReC2007. Excellent support was provided by the German Air Traffic Control for the numerous and non-routine aircraft missions in very busy airspace. The tireless efforts of all aircraft crews and scientists in the field are highly appreciated.

Local authorities, particularly the mayors of the communities Baiersbronn, Seebach, Sasbachwalden, and Deckenpfronn, and several land owners in the experiment region, in particular the Flugsportverein Sindelfinden e.V. and the municipal sewage plant in Achern provided most valuable assistance. All this support is acknowledged with gratitude.

\section{Appendix}

\section{Abbreviations}

\begin{tabular}{|c|c|c|c|}
\hline \multirow{2}{*}{\multicolumn{2}{|c|}{$\begin{array}{l}\text { Christian Ehmann, Johannes Dahl, and Bernhard Mühr. } \\
\text { EUMETNET and EUCOS provided additional targeting } \\
\text { measurements within ETReC2007. Excellent support was }\end{array}$}} & \multicolumn{2}{|c|}{ Abbreviations (continued) } \\
\hline & & DAP & Data Assimilation and Predictability \\
\hline \multirow{4}{*}{\multicolumn{2}{|c|}{$\begin{array}{l}\text { provided by the German Air Traffic Control for the } \\
\text { numerous and non-routine aircraft missions in very busy } \\
\text { airspace. The tireless efforts of all aircraft crews and scientists } \\
\text { in the field are highly appreciated. }\end{array}$}} & DFG & German Research Foundation (Deutsche \\
\hline & & & Forschungsgemeinschaft) \\
\hline & & DIAL & Differential Absorption Lidar \\
\hline & & DLR & German Aerospace Centre \\
\hline \multirow{2}{*}{\multicolumn{2}{|c|}{$\begin{array}{l}\text { Local authorities, particularly the mayors of the } \\
\text { communities Baiersbronn, Seebach, Sasbachwalden, and }\end{array}$}} & DOP & D-PHASE Operations Period \\
\hline & & DOW & Doppler-on-Wheels \\
\hline \multirow{3}{*}{\multicolumn{2}{|c|}{$\begin{array}{l}\text { Deckenpfronn, and several land owners in the experiment } \\
\text { region, in particular the Flugsportverein Sindelfinden e.V. } \\
\text { and the municipal sewage plant in Achern provided most } \\
\text { valuable assistance. All this support is acknowledged with } \\
\text { gratitude. }\end{array}$}} & D-PHASE & $\begin{array}{l}\text { Demonstration of Probabilistic Hydro- } \\
\text { logical and Atmospheric Simulation of } \\
\text { flood Events in the Alpine region }\end{array}$ \\
\hline & & DT/INSU & Division Technique de l'INSU \\
\hline & & DWD & Deutscher Wetterdienst (German \\
\hline \multirow{2}{*}{\multicolumn{2}{|c|}{ Appendix }} & & Meteorological Service) \\
\hline & & E-AMDAR & EUMETNET AMDAR Programme \\
\hline \multicolumn{2}{|c|}{ Abbreviations } & ECMWF & $\begin{array}{l}\text { European Centre for Medium-range } \\
\text { Weather Forecasts }\end{array}$ \\
\hline $\mathrm{ABL}$ & Atmospheric Boundary Layer & EnKF & Ensemble Kalman Filter \\
\hline $\mathrm{ACM}$ & Aerosol and Cloud Microphysics & EPS & Ensemble Prediction System \\
\hline ADMIRARI & $\begin{array}{l}\text { ADvanced MIcrowave RAdiometer for } \\
\text { Rain Identification }\end{array}$ & EOST & $\begin{array}{l}\text { Ecole et Observatoire des Sciences de la } \\
\text { Terre }\end{array}$ \\
\hline AERI & $\begin{array}{l}\text { Atmospheric Emitted Radiance Interfer- } \\
\text { ometer }\end{array}$ & $\begin{array}{l}\text { ETKF } \\
\text { FUCOS }\end{array}$ & Ensemble Transform Kalman Filter \\
\hline AMDAR & Aircraft Meteorological Data Relay & & tem \\
\hline AMF & ARM Mobile Facility & EUFAR & European Fleet for Airborne Research \\
\hline ANR & Agence Nationale de la Recherche & EUMETNET & The Network of European Meteorologi- \\
\hline ARM & Atmospheric Radiation Measurement & & cal Services \\
\hline AROME & $\begin{array}{l}\text { Application of Research to Operational } \\
\text { at Mesoscale }\end{array}$ & EUMETSAT & $\begin{array}{l}\text { EUropean organisation for the exploita- } \\
\text { tion of METeorological SATellites }\end{array}$ \\
\hline ARPA SIMC & $\begin{array}{l}\text { Agenzia Regionale Prevenzione e Ambi- } \\
\text { ente Servizio Idro-Meteo-Clima }\end{array}$ & ETReC (2007) & $\begin{array}{l}\text { European THORPEX Regional Cam- } \\
\text { paign }\end{array}$ \\
\hline ASR & Atmospheric System Research & FAAM & Facility for Airborne Atmospheric Mea- \\
\hline ATC & Air Traffic Control & & surements \\
\hline AWS & Automated weather station & FDP & Forecast Demonstration Project \\
\hline BLIDS & Blitz-Informations-Dienst & FTIR & Fourier-Transform InfraRed \\
\hline \multirow[t]{3}{*}{ BMLFUW } & Federal Ministry of Agriculture, Forestry, & FZJ & Forschungszentrum Jülich \\
\hline & Environment and Water Management, & FZK & Forschungszentrum Karlsruhe \\
\hline & Austria & GFS & Global Forecast System \\
\hline CAPE & Convective Available Potential Energy & GFZ & Helmholtz-Centre Potsdam, German \\
\hline $\mathrm{CBL}$ & Convective Boundary Layer & & Research Center for Geosciences \\
\hline $\mathrm{Ch}$ & Channel & GOP & General Observations Period \\
\hline CI & Convective Initiation & GPS & Global Positioning System \\
\hline CIN & Convective Inhibition & GRIB & Gridded Binary (data format) \\
\hline CNES & Centre National d'Etudes Spatiales & GTS & Global Telecommunication System \\
\hline \multirow[t]{3}{*}{ CNR-IMAA } & Consglio Nazionale delle Ricerche, Isti- & GWA & Grosswetterlage \\
\hline & tuto di Meteorologie per l'Analisi Ambi- & HATPRO & Humidity and Temperature Profiler \\
\hline & entale & HyMeX & Hydrological Cycle in the Mediterranean \\
\hline \multirow[t]{2}{*}{ CNRS } & Centre Nationale de la Recherche Scien- & & Experiment \\
\hline & tific & IASI & Infrared Atmospheric Sounding Interfer- \\
\hline \multirow[t]{2}{*}{ COPS } & Convective and Orographically-induced & & ometer \\
\hline & Precipitation Study & ICAM & International Conference on Alpine \\
\hline \multirow[t]{2}{*}{ CORDEX } & Coordinated Regional climate Down- & & Meteorology \\
\hline & scaling Experiment & IfT & Institute for Tropospheric Research \\
\hline COSMO & Consortium for Small-scale Modelling & IGN & Institut Géographique National \\
\hline CSIP & Convective Storm Initiation Project & IGBP & International Geosphere-Biosphere Pro- \\
\hline DA & Data Assimilation & & gramme \\
\hline
\end{tabular}




\begin{tabular}{|c|c|c|c|}
\hline \multicolumn{2}{|c|}{ Abbreviations (continued) } & \multicolumn{2}{|c|}{ Abbreviations (continued) } \\
\hline \multirow{3}{*}{$\begin{array}{l}\text { IHOP } \\
\text { IMK }\end{array}$} & International $\mathrm{H}_{2} \mathrm{O}$ Project & PQP & Precipitationis Quantitativae Predictio \\
\hline & Institute for Meteorology and Climate & & (latin for QPF) \\
\hline & Research, Karlsruhe & PRINCE & PRediction, IdeNtification and tracking \\
\hline IMRE & $\begin{array}{l}\text { Integrated Mesoscale Research Environ- } \\
\text { ment }\end{array}$ & PrQPF & $\begin{array}{l}\text { of Convective Cells } \\
\text { Probabilistic Quantitative Precipitation }\end{array}$ \\
\hline INSU & Institut des Sciences de l’Univers & & Forecasting \\
\hline IOP & Intensive Observations Period & PV & Potential Vorticity \\
\hline \multirow[t]{2}{*}{ IPM } & Institute of Physics and Meteorology, & QPF & Quantitative Precipitation Forecasting \\
\hline & University of Hohenheim & RASS & Radio Acoustic Sounding System \\
\hline IR & Infrared & RDP & Research and Development Project \\
\hline IWV & Integrated water vapour & RGB & Red-Green-Blue \\
\hline JDC & Joint D-PHASE-COPS (dataset) & RHI & Range-Height-Indicator \\
\hline KIT & Karlsruhe Institute of Technology & $\mathrm{RR}$ & Rotational Raman \\
\hline \multirow[t]{2}{*}{ KNMI } & Koninklijk Nederlands Meteorologisch & RS & Radiosonde station \\
\hline & Instituut & RSS & Rapid Scan Service \\
\hline LAM & Limited-Area Model & RUC & Rapid Update Cycle \\
\hline LaMP & Laboratoire de Météorologie Physique & RWP & Radar Wind Profiler \\
\hline LAREG & Laboratoire de Recherche en Géodésie & SAFIRE & Service des Avions Français Instrumentés \\
\hline \multirow[t]{2}{*}{ LATMOS } & Laboratoire Atmosphère, Milieux, & & pour la Recherche en Environnement \\
\hline & Observations Spatiales & SIMC & Servizio Idro-Meteo-Clima \\
\hline \multirow[t]{2}{*}{ LDL } & Laboratoire Dynamique de la Litho- & SOD & Science Overview Document \\
\hline & sphere & SOP & Special Observations Period \\
\hline LFUB & Bayerisches Umweltlandesamt, Germany & SPP & Priority Program (Schwerpunktpro- \\
\hline LINET & Lightning Location Network & & gramm) \\
\hline LMD & Laboratoire de Météorologie Dynamique & STD & Slant total delay \\
\hline LOS & Line-of-Sight & SYNOP & Synoptic observation \\
\hline \multirow[t]{3}{*}{ LUBW } & Landesanstalt für Umwelt, Messungen & TARA & Transportable Atmospheric Radar \\
\hline & und Naturschutz, Baden-Württemberg, & THORPEX & THe Observing system Research and \\
\hline & & & Predictability EXperiment \\
\hline LWP & Liquid Water Path & TIGGE & THORPEX Interactive Grand Global \\
\hline MAP & Mesoscale Alpine Programme & & Ensemble \\
\hline MCS & Mesoscale Convective System & TRACKS & Transport and Chemistry of Convective \\
\hline METOP & Meteorological Operational (satellite) & & Systems \\
\hline MICCY & $\begin{array}{l}\text { Microwave Radiometer for Cloud Car- } \\
\text { tography }\end{array}$ & TRACT & $\begin{array}{l}\text { Transport of Air pollutants over Com- } \\
\text { plex Terrain }\end{array}$ \\
\hline MM5 & Mesoscale Model 5 & TReSS & Transportable Remote Sensing Station \\
\hline \multirow[t]{2}{*}{ MPIfC } & Max Planck Institute for Chemistry, & TUD & Delft University of Technology \\
\hline & Mainz & UB & University of Bonn \\
\hline MRR & Micro Rain Radar & UBal & University of the Balearic Islands \\
\hline MSG & Meteosat Second Generation & UBIMET & Meteomedia Network \\
\hline MWFR & Mesoscale Weather Forecasting Research & UBT & University of Bayreuth \\
\hline MWL & Multi-Wavelength Lidar & UC & University of Cologne \\
\hline MWR & Microwave Radiometer & UF & University of Freiburg \\
\hline \multirow[t]{2}{*}{ NCAR } & National Center for Atmospheric & UHF & Ultra-High Frequency \\
\hline & Research & UHH & University of Hamburg \\
\hline NCAS & National Center for Atmospheric Science & $\mathrm{UHOH}$ & University of Hohenheim \\
\hline \multirow[t]{2}{*}{ NCEP } & National Centers for Environmental & UK & United Kingdom \\
\hline & Prediction & UL & University of Leeds \\
\hline NERC & Natural Environment Research Council & UM & University of Munich \\
\hline NWP & Numerical Weather Prediction & UMan & University of Manchester \\
\hline $\mathrm{PBC}$ & Particle Backscatter Coefficient & UNIBAS & University of Basilicata \\
\hline PI & Principle Investigator & US & United States \\
\hline POLDIRAD & Polarisation Diversity Radar of DLR & USal & University of Salford \\
\hline \multirow[t]{2}{*}{ PPL } & Precipitation Processes and their Life & UV & University of Vienna \\
\hline & Cycle & VERA & Vienna Enhanced Resolution Analysis \\
\hline
\end{tabular}




\begin{tabular}{ll} 
Abbreviations (continued) \\
\hline VERTIKATOR & Vertikaler Austausch und Orographie \\
WACR & W-band ARM Cloud Radar \\
WALES & Water Vapour Lidar Experiment in Space \\
WCRP & World Climate Research Programme \\
WDCC & World Data Center for Climate \\
WiLi & Wind Lidar \\
WG & Working Group \\
WMO & World Meteorological Organization \\
WRF & Weather Research and Forecasting \\
& (model) \\
WTR & Wind-temperature-radar \\
WV & Water Vapour \\
WWRP & World Weather Research Programme \\
ZTD & Zenith Total Delay
\end{tabular}

\section{References}

Ament F, Weusthoff T, Arpagaus M. 2010. Evaluation of MAP D-PHASE heavy precipitation alerts in Switzerland during summer 2007. Atmos. Res. DOI: 10.1016/j.atmosres.2010.06.007.

Aoshima F, Behrendt A, Bauer H-S, Wulfmeyer V. 2008. Statistics of convection initiation by use of the Meteosat Rapid Scan Service during the Convection and Orographically induced Precipitation Study. Meteorol. Z. 17: 921-930.

Arpagaus M, Rotach MW, Ambrosetti P, Ament F, Appenzeller C, Bauer H-S, Behrendt A, Bouttier F, Buzzi A, Corazza M, Davolio S, Denhard M, Dorninger M, Fontannaz L, Frick J, Fundel F, Germann U, Gorgas T, Grossi G, Hegg C, Hering A, Jaun S, Keil C, Liniger MA, Marsigli C, McTaggart-Cowan R, Montani A, Mylne K, Panziera L, Ranzi R, Richard E, Rossa A, Santos-Muñoz D, Schär C, Seity Y, Staudinger M, Stoll M, Vogt S, Volkert H, Walser A, Wang Y, Werhahn J, Wulfmeyer V, Wunram C, Zappa M. 2009. MAP D-PHASE: 'Demonstrating forecast capabilities for flood events in the Alpine region'. Report to WWRP. Veröffentlichungen der MeteoSchweiz. No 78. MeteoSchweiz: Zurich.

Barthlott C, Corsmeier U, Meissner C, Braun F, Kottmeier C. 2006. The influence of mesoscale circulation systems on triggering convective cells over complex terrain. Atmos. Res. 81: 150-175.

Barthlott C, Schipper JW, Kalthoff N, Adler B, Kottmeier C, Blyth AM, Mobbs S. 2010. Model representation of boundary-layer convergence triggering deep convection over complex terrain: A case-study from COPS. Atmos. Res. 95: 172-185, DOI: 10.1016/j.atmosres.2009.02.010.

Barthlott C, Burton R, Kirshbaum D, Hanley K, Richard R, Chaboreau JP, Trentmann J, Kern B, Bauer H-S, Schwitalla T, Keil C, Seity Y, Gadian A, Blyth AM, Mobbs S, Flamant C, Handwerker J. 2011. Initiation of deep convection at marginal instability in an ensemble of mesoscale models: A case-study from COPS. Q. J. R. Meteorol. Soc. 137: 000-000.

Bauer H-S, Grzeschik M, Zus F, Schwitalla T, Wulfmeyer V. 2009a. 'dphase_mm5_2_ct: MM5 model forecast with $2 \mathrm{~km}$ horizontal resolution driven by ECMWF operational forecast run by UHOH for the MAP D-PHASE project'. World Data Center for Climate: Hamburg. http://cerawww.dkrz.de/WDCC/ui/BrowseExperiments.jsp?proj=DPHASE.

Bauer H-S, Grzeschik M, Zus F, Schwitalla T, Wulfmeyer V. 2009b. 'dphase_mm5_2_4d: MM5 model forecast with $2 \mathrm{~km}$ horizontal resolution based on 4DVAR assimilation of GPS data run by UHOH for the MAP D-PHASE project'. World Data Center for Climate: Hamburg. http://cerawww.dkrz.de/WDCC/ui/BrowseExperiments.jsp?proj=DPHASE.

Bauer H-S, Zus F, Wulfmeyer V, Schwitalla T, Grzeschik M. 2010. Operational assimilation of GPS slant path delay measurements into the MM5 4D-Var system. Tellus A. DOI: 10.1111/j.16000870.2010.00489.x.

Bauer H-S, Weusthoff T, Dorninger M, Wulfmeyer V, Gorgas T, Arpagaus M, Schwitalla T, Warrach-Sagi K. 2011. Predictive skill of the D-PHASE multi-model ensemble in the COPS region. Q. J. $R$. Meteorol. Soc. 137: 000-000.
Behrendt A, Wulfmeyer V, Di Girolamo P, Kiemle C, Bauer H-S, Schaberl T, Summa D, Whiteman DN, Demoz BB, Browell EV, Ismail S, Ferrare R, Kooi S, Ehret G, Wang J. 2007a. Intercomparison of water vapor data measured with lidar during IHOP_2002, Part 1: Airborne to ground-based lidar systems and comparisons with chilled-mirror hygrometer radiosondes. J. Atmos. Oceanic Technol. 24(1): 3-21, DOI: 10.1175/JTECH1924.1.

Behrendt A, Wulfmeyer V, Kiemle C, Ehret G, Flamant C, Schaberl T, Bauer H-S, Kooi S, Ismail S, Ferrare R, Browell EV, Whiteman DN. 2007b. Intercomparison of water vapor data measured with lidar during IHOP_2002, Part 2: Airborne to airborne systems. J. Atmos. Oceanic Technol. 24(1): 22-39, DOI: 10.1175/JTECH1925.1.

Behrendt A, Wulfmeyer V, Riede A, Wagner G, Pal S, Bauer H, Radlach M, Späth F. 2009. Three-dimensional observations of atmospheric humidity with a scanning differential absorption lidar. In Remote Sensing of Clouds and the Atmosphere XIV. Picard $\mathrm{RH}$, Schäfer K, Comeron A (eds.) SPIE Conference Proceeding 7475. Art. No. 74750 L. DOI: 10.1117/12.835143.

Behrendt A, Pal S, Aoshima F, Bender M, Blyth A, Corsmeier U, Cuesta J, Dick G, Dorninger M, Flamant C, Di Girolamo P, Gorgas T, Huang Y, Kalthoff N, Khodayar S, Mannstein H, Träumner K, Wieser A, Wulfmeyer V. 2011. Observation of convection initiation processes with a suite of state-of-the-art research instruments during COPS IOP 8b. Q. J. R. Meteorol. Soc. 137(S1): 81-100, DOI: 10.1002/qj.758.

Bennett LJ, Blyth AM, Burton RR, Gadian AM, Weckwerth TM, Behrendt A, Di Girolamo P, Dorninger M, Lock S-J, Smith VH, Mobbs SD. 2011. Initiation of convection over the Black Forest mountains during COPS IOP15a. Q. J. R. Meteorol. Soc. 137(S1): $176-189$.

Bhawar R, Di Girolamo P, Summa D, Flamant C, Althausen D, Behrendt A, Kiemle C, Bosser P, Cacciani M, Champollion C, Di Iorio T, Engelmann R, Herold C, Pal S, Riede A, Wirth M, Wulfmeyer V. 2011. The water vapour intercomparison effort in the framework of the Convective and Orographically-induced Precipitation Study: Airborne-to-ground-based and airborne-toairborne Lidar systems. Q. J. R. Meteorol. Soc. 137(S1): 325-347.

Bissolli P, Dittmann E. 2001. The objective weather type classification of the German Weather Service and its possibilities of application to environmental and meteorological investigations. Meteorol. Z. 10: 253-260.

Browning KA, Morcrette CJ, Nicol J, Blyth AM, Bennett LJ, Brooks BJ, Marsham J, Mobbs SD, Parker DJ, Perry F, Clark PA, Ballard SP, Dixon MA, Forbes RM, Lean HW, Li Z, Roberts NM, Corsmeier U, Barthlott C, Deny B, Kalthoff N, Khodayar S, Kohler M, Kottmeier C, Kraut S, Kunz M, Lenfant J, Wieser A, Agnew JL, Bamber D, McGregor J, Beswick KM, Gray MD, Norton E, Ricketts HMA, Russell A, Vaughan G, Webb AR, Bitter M, Feuerle T, Hankers R, Schulz H, Bozier KE, Collier CG, Davies F, Gaffard C, Hewison TJ, Ladd DN. Slack EC, Waight J, Ramatschi M, Wareing DP, Watson RJ. 2007. The Convective Storm Initiation Project. Bull. Am. Meteorol. Soc. 88: 1939-1955, DOI: 10.1175/BAMS-88-12-1939.

Bruneau D, Quaglia P, Flamant C, Meissonnier M, Pelon J. 2001. The airborne lidar LEANDRE II for water-vapor profiling in the troposphere. I. System description. Appl. Opt. 40: 3450-3475.

Chaboureau J-P, Guichard F, Redelsperger J-L, Lafore J-L. 2004. The role of stability and moisture in the diurnal cycle of convection over land. Q. J. R. Meteorol. Soc. 130: 3105-3117.

Chaboureau J-P, Richard E, Pinty J-P, Flamant C, Di Girolamo P, Kiemle C, Behrendt A, Chepfer H, Chiriaco M, Wulfmeyer V. 2011. Long-range transport of Saharan dust and its radiative impact on precipitation forecast over western Europe. Q. J. R. Meteorol. Soc. 137(S1): 236-251.

Champollion C, Flamant C, Bock O, Masson F, Turner DD, Weckwerth TM. 2009. Mesoscale GPS tomography applied to the 12 June 2002 convective initiation event of IHOP 2002. Q. J. R. Meteorol. Soc. 135: 645-662.

Chu J, Warrach-Sagi K, Wulfmeyer V, Schwitalla T, Bauer HS. 2010. 'Regional climate simulation (1989-2009) with WRF in the CORDEX-Europe domain'. In Proceedings of 10th Annual Meeting of the European Meteorological Society (EMS), 13-17 September 2010, Zurich, Switzerland.

Corsmeier U, Kalthoff N, Barthlott C, Aoshima F, Behrendt A, Di Girolamo P, Dorninger M, Handwerker J, Kottmeier C, Mahlke H, Mobbs SD, Norton EG, Wickert J, Wulfmeyer V. 2011. Processes driving deep convection over complex terrain: A multi-scale analysis of observations from COPS IOP 9c. Q. J. R. Meteorol. Soc. 137(S1): 137-155, DOI:10.1002/qj.754.

Crewell S, Löhnert U. 2003. Accuracy of cloud liquid water path from ground-based microwave radiometery. Part II, sensor accuracy and synergy. Radio Sci. 38: 8042, DOI:10.1029/2002RS002634. 
Crewell S, Mech M, Reinhardt T, Selbach C, Betz H-D, Brocard E, Dick G, O'Connor E, Fischer J, Hanisch T, Hauf T, Hünerbein A Delobbe L, Mathes A, Peters G, Wernli H, Wulfmeyer V. 2008. General Observation Period 2007: Concept and first results. Meteorol. Z. 17: 849-866.

de Haan S, van der Marel H. 2008. Observing three dimensional water vapour using a surface network of GPS receivers. Atmos. Chem. Phys. Dist. 8: $17193-17235$.

Dick G, Gendt G, Reigber C. 2001. First experience with near-realtime water vapour estimation in a German GPS network. J. Atmos Solar-Terr. Phys. 63: 1295-1304.

Dorninger M, Schneider S, Steinacker R. 2008. On the interpolation of precipitation data over complex terrain. Meteorol. Atmos. Phys. 101: 175-189, DOI: 10.1007/s00703-008-0287-6.

Dorninger M, Gorgas T. 2010. 'Using the JDC (Joint D-PHASE COPS) observational data set for high-resolution analysis and ensemble analysis'. In Proceedings of 14th AMS Conference on Mountain Meteorology, Lake Tahoe, USA, 30 August-3 September. Amer. Meteorol. Soc: Boston.

Ebell K, Löhnert U, Crewell S, Turner DD. 2009. On characterizing the error in a remotely sensed liquid water content profile. Atmos. Res. 98(1): 57-68, DOI:10.1016/j.atmosres.2010.06.002.

Ebell K, Crewell S, Löhnert U, Turner DD, O'Connor EJ. 2011. Cloud statistics and cloud-radiative effect for a low-mountain site. Q. J. R Meteorol. Soc. 137: 000-000.

Eigenmann R, Kalthoff N, Foken T, Dorninger M, Kohler M, Legain D, Pigeon G, Piguet B, Schüttemeyer D, Traulle O. 2011. Surface energy balance and turbulence network during COPS. Q. J. R. Meteorol. Soc 137: 000-000.

Feldmann H, Früh B, Schädler G, Panitz H-J, Keuler K, Jacob D, Lorenz P. 2008. Evaluation of the precipitation for southwestern Germany from high-resolution simulations with regional climate models. Meteorol. Z. 17: 455-465.

Frei C, Schär C. 1998. A precipitation climatology of the Alps from high-resolution rain-gauge observations. Int. J. Climatol. 18: 873-900.

Gendt G, Dick G, Reigber C, Tomassini M, Liu Y, Ramatschi M. 2004 Near-real-time GPS water vapor monitoring for numerical weather prediction in Germany. J. Meteorol. Soc. Japan 82: 361-370.

Giuchard F, Petch JC, Redelsperger J-L, Bechthold P, Chaboureau J-P Cheinet S, Grabowski W, Grenier H, Jones CG, Köhler M, Piriou JM, Tailleux R, Tomasini M. 2004. Modelling the diurnal cycle of deep precipitating convection over land with cloud-resolving and single-column models. Q. J. R. Meteorol. Soc. 130: 3139-3172.

Gorgas T, Dorninger M, Steinacker R. 2009. High-resolution analyses based on the D-PHASE and COPS GTS and non-GTS data sets. Ann Meteorol. 44: 94-95. Deutscher Wetterdienst: Offenbach, Germany http://www.pa.op.dlr.de/icam2009/extabs.

Groenemeijer P, Barthlott C, Behrendt A, Corsmeier U, Handwerker J Kohler M, Kottmeier C, Mahlke H, Pal S, Radlach M, Trentmann J Wieser A, Wulfmeyer V. 2009. Multi-sensor measurements of a convective storm cluster over a low mountain range: Adaptive observations during PRINCE. Mon. Weather Rev. 137: 585-602, DOI: $10.1175 / 2008$ MWR2562.1.

Grzeschik M, Bauer H-S, Wulfmeyer V. 2008. Four-dimensional analysis of water-vapor Raman lidar data and their impact on mesoscale forecasts. J. Atmos. Oceanic Technol. 25: 1437-1453, DOI: 10.1175/2007JTECHA974.1.

Hauck C, Barthlott C, Krauss L, KalthoffN. 2011. Soil moisture variability and its influence on convective precipitation over complex terrain. $Q$. J. R. Meteorol. Soc. 137: 000-000

Hense A, Wulfmeyer V. 2008. The German Priority Program SPP1167 'Quantitative Precipitation Forecast'. Meteorol. Zeitschrift. 17: $703-705$.

Junkermann W, Hagemann R, Vogel B. 2011. Nucleation in the Karlsruhe plume during the COPS/TRACKS-Lagrange experiment. Q. J. $R$ Meteorol. Soc. 137(S1): 267-274, DOI: 10.1002/qj.753.

Kalthoff N, Adler B, Barthlott C, Corsmeier U, Mobbs S, Crewell S, Träumner K, Kottmeier C, Wieser A, Smith V. 2009. The impact of convergence zones on the initiation of deep convection: A case-study from COPS. Atmos. Res. 93: 680-694, DOI: 10.1016/j.atmosres.2009.02.010.

Kalthoff N, Kohler M, Barthlott C, Adler B, Mobbs SD, Corsmeier U, Träumner K, Foken T, Eigenmann R, Krauss L, Khodayar S, Di Girolamo P. 2011. The dependence of convection-related parameters on surface and boundary-layer conditions over complex terrain. Q. J. R. Meteorol. Soc. 137(S1): 70-80, DOI: 10.1002/qj.686.

Keil C, Craig G. 2009. Sources of uncertainty determined by high-resolution ensemble modelling. Ann. Meteorol. 44: Deutscher Wetterdienst, Offenbach, Germany. 118-119. http://www.pa.op.dlr.de/icam2009/extabs.
Kiemle C, Wirth M, Fix A, Rahm S, Corsmeier U, Di Girolamo P. 2011. Latent heat fluxes over complex terrain from airborne water vapour and wind lidars. Q. J. R. Meteorol. Soc. 137: 000-000.

Kleinn J, Frei C, Gurtz J, Lüthi D, Vidale PL, Schär C. 2005. Hydrologic simulations in the Rhine basin driven by a regional climate model. J. Geophys. Res. 110: D04102, DOI: 10.1029/2004JD005143.

Kossmann M, Vögtlin R, Corsmeier U, Vogel B, Fiedler F, Binder H-J, Kalthoff N, Beyrich F. 1998. Aspects of the convective boundary-layer structure over complex terrain. Atmos. Environ. 32: 1323-1348.

Kottmeier C, Kalthoff N, Barthlott C, Corsmeier U, Van Baelen J A, Behrendt A, Behrendt R, Blyth AM, Coulter R, Crewell S, Dorninger M, Flamant C, Foken T, Hagen M, Hauck C, Höller H, Konow H, Kunz M, Mahlke H, Mobbs S, Richard E, Steinacker R, Weckwerth T, Wieser A, Wulfmeyer V. 2008. Mechanisms initiating deep convection over complex terrain during COPS. Meteorol. Z. 17: 931-948.

Long CN, Turner DD. 2008. A method for continuous estimation of clear-sky downwelling longwave radiative flux developed using ARM surface measurements. J. Geophys. Res. 113: D18206, DOI: 10.1029/2008JD009936.

Long CN, Ackerman TP, Gaustad KL, Cole JNS. 2006. Estimation of fractional sky cover from broadband shortwave radiometer measurements. J. Geophys. Res. 111: D11204, DOI: 10.1029/2005JD006475.

Miller M, Slingo A. 2007. The ARM mobile facility and its first international deployment: Measuring radiative flux divergence in West Africa. Bull. Am. Meteorol. Soc. 88: 1229-1244, DOI: 10.1175/BAMS88-8-1229.

Paulat M, Frei C, Hagen M, Wernli H. 2008. A gridded dataset of hourly precipitation in Germany: Its construction, climatology and application. Special Issue on Quantitative Precipitation Forecasting. Meteorol. Z. 17: 719-732.

Radlach M, Behrendt A, Wulfmeyer V. 2008. Scanning rotational Raman lidar at $355 \mathrm{~nm}$ for the measurement of tropospheric temperature fields. Atmos. Chem. Phys. 8: 159-169.

Reverdy M, Van Baelen J, Walpersdorf A, Dick G, Hagen M, Richard E. 2009. Water vapor fields retrieval with tomography software. Ann. Meteorol. 44: Deutscher Wetterdienst, Offenbach, Germany. 144-145. http://www.pa.op.dlr.de/icam2009/extabs.

Richard E, Buzzi A, Zängl G. 2007. Quantitative precipitation forecasting in the Alps: The advances achieved by the Mesoscale Alpine Programme. Q. J. R. Meteorol. Soc. 133: 831-846.

Richard E, Flamant C, Bouttier F, Van Baelen J, Champollion C, Argence S, Arnault J, Barthlott C, Behrendt A, Bosser P, Brousseau P, Chaboureau JP, Corsmeier U, Cuesta J, Di Girolamo P, Hagen M, Kottmeier C, Limnaios P, Masson F, Pigeon G, Pointin Y, Seity Y, Wulfmeyer V. 2009. La campagne COPS: Initiation et cycle de vie de la convection en region montagneuse. La Météorologie. 64: 32-42.

Richard E, Grzeschik M, Bielli S, Flamant C, Champollion C, Kiemle C. 2010. 'Assimilation of airborne lidar water vapor observations during COPS'. In Proceedings of 14th AMS Conference on Mountain Meteorology, Lake Tahoe, USA, 30 August-3 September 2010.

Richard E, Chaboureau J-P, Flamant C, Champollion C, Hagen M, Schmidt K, Kiemle C, Corsmeier C, Barthlott C. 2011. Forecasting summer convection over the Black Forest: A case-study from the COPS experiment. Q. J. R. Meteorol. Soc. 137: 000-000.

Rotach MW, Ambrosetti P, Ament F, Appenzeller C, Arpagaus M, Bauer H-S, Behrendt A, Bouttier F, Buzzi A, Corazza M, Davolio S, Denhard M, Dorninger M, Fontannaz L, Frick J, Fundel F, Germann U, Gorgas T, Hegg C, Hering A, Keil C, Liniger MA, Marsigli C, McTaggart-Cowan R, Montani A, Mylne K, Ranzi R, Richard E, Rossa A, Santos-Muñoz D, Schär C, Seity Y, Staudinger M, Stoll M, Volkert H, Walser A, Wang Y, Werhahn J, Wulfmeyer V, Zappa M. 2009a. MAP D-PHASE: Real-time demonstration of weather forecast quality in the Alpine region. Bull. Am. Meteorol. Soc. 90: 1321-1336, DOI:10.1175/2009BAMS2776.1.

Rotach MW, Ambrosetti P, Ament F, Appenzeller C, Arpagaus M, Bauer H-S, Behrendt A, Bouttier F, Buzzi A, Corazza M, Davolio S, Denhard M, Dorninger M, Fontannaz L, Frick J, Fundel F, Germann U, Gorgas T, Hegg C, Hering A, Keil C, Liniger MA, Marsigli C, McTaggart-Cowan R, Montani A, Mylne K, Ranzi R, Richard E, Rossa A, Santos-Muñoz D, Schär C, Seity Y, Staudinger M, Stoll M, Volkert H, Walser A, Wang Y, Werhahn J, Wulfmeyer V, Zappa M. 2009b. Supplement: Additional applications of the D-PHASE data sets. Bull. Am. Meteorol. Soc. 90: (electronic supplement) 28-32.

Rotunno R, Houze RA. 2007. Lessons on orographic precipitation from the Mesoscale Alpine Programme. Q. J. R. Meteorol. Soc. 133: 811-830.

Schäfler A, Dörnbrack A, Kiemle C, Rahm S, Wirth M. 2010. Tropospheric water vapor transport as determined from airborne lidar measurements. J. Atmos. Oceanic Technol. DOI: 10.1175/2010JTECHA1418.1. 
Schwarb M, Daly C, Frei C, Schär C. 2001. Mean annual and seasonal precipitation throughout the European Alps 1971-1990. In Hydrological Atlas of Switzerland. Plates 2.6, 2.7.

Schwitalla T, Zängl G, Bauer H-S, Wulfmeyer V. 2008. Systematic errors of QPF in low-mountain regions. Meteorol. Z. 17: 903-919.

Schwitalla T, Bauer H-S, Wulfmeyer V. 2011. High-resolution simulation over central Europe using GPS-ZTD observations with WRF 3D-Var: A case-study of COPS IOP9c. Q. J. R. Meteorol. Soc. 137(S1): 156-175.

Steinacker R, Ratheiser M, Bica B, Chimani B, Dorninger M, Gepp W, Lotteraner C, Schneider S, Tschannett S. 2006. A mesoscale data analysis and downscaling method over complex terrain. Mon. Weather Rev. 134: 2758-2771.

Trentmann J, Keil C, Salzmann M, Barthlott C, Bauer H-S, Schwitalla T, Lawrence MG, Leuenberger D, Wulfmeyer V, Corsmeier U, Kottmeier C, Wernli H. 2009. Multi-model simulations of a convective situation in low-mountain terrain in central Europe. Meteorol. Atmos. Phys. 103: 95-103, DOI: 10.1007/s0073-008-0323-6.

Turner DD, Clough SA, Liljegren JC, Clothiaux EE, Cady-Pereira K, Gaustad KL. 2007. Retrieving liquid water path and precipitable water vapor from Atmospheric Radiation Measurement (ARM) microwave radiometers. IEEE Trans. Geosci. Remote Sensing. 45: 3680-3690, DOI: 10.1109/TGRS.2007.903703

Turner DD, Löhnert U, Cadeddu M, Crewell S, Vogelmann A. 2009. Modifications to the water vapor continuum in the microwave suggested by ground-based $150 \mathrm{GHz}$ observations. IEEE Trans. Geosci. Remote Sensing. 47: 3326-3337, DOI:10.1109/TGRS.2009.202262.

Van Baelen J, Tridon F, Pointin Y. 2009. Simultaneous X-band and $\mathrm{K}$-band study of precipitation to derive specific $\mathrm{Z}-\mathrm{R}$ relationships. Atmos. Res. 94: 596-605, DOI: 10.1016/j.atmosres.2009.04.003.

Volkert H. 2009. The summer of COPS-2007: Multi-scale dynamics visualized by variable speed time-lapse satellite imagery. Ann. Meteorol. 44: 244-245. Deutscher Wetterdienst, Offenbach, Germany. http://www.pa.op.dlr.de/icam2009/extabs.

Volkert H, Gutermann T. 2007. Inter-domain cooperation for mesoscale atmospheric laboratories: The Mesoscale Alpine Programme as a rich study case. Q. J. R. Meteorol. Soc. 133: 949-967.

Warrach-Sagi K, Wulfmeyer V. 2010. Streamflow data assimilation for soil moisture analysis. Geosci. Model Dev. Discuss. 2: 551-579.

Weckwerth TM, Parsons DB. 2006. A review of convection initiation and motivation for IHOP_2002. Mon. Weather Rev. 134: 5-22.

Weckwerth TM, Wilson JW, Wakimoto RM. 1996. Thermodynamic variability within the convective boundary layer due to horizontal convective rolls. Mon. Weather Rev. 124: 769-784.

Weckwerth TM, Parsons DB, Koch SE, Moore JA, LeMone MA, Demoz BB, Flamant C, Geerts B, Wang J, Feltz WF. 2004. An overview of the International $\mathrm{H}_{2} \mathrm{O}$ Project (IHOP_2002) and some preliminary highlights. Bull. Am. Meteorol. Soc. 85: 253-277.

Weckwerth TM, Wilson JW, Hagen M, Emerson TJ, Grebe L. 2011. Radar climatology of the COPS region. Q. J. R. Meteorol. Soc. 137(S1): 31-41.

Wernli H, Pfahl S, Trentmann J, Zimmer M. 2010. How representative were the meteorological conditions during the COPS field experiment in summer 2007? Meteorol. Z. 19: 619-630.
Weusthoff T, Ament F, Arpagaus M, Rotach MW. 2010. Assessing the benefits of convection permitting models by Fuzzy Verification - examples from MAP D-PHASE. Mon. Weather Rev. 138: $3418-3433$

Wirth M, Fix A, Mahnke P, Schwarzer H, Schrandt F, Ehret G. 2009. The airborne multi-wavelength water vapor differential absorption lidar WALES: system design and performance. Appl. Phys. B. 96: 201-213, DOI:10.1007/s00340-009-3365-7.

WMO. 2009a. The World Climate Research Programme Implementation Plan (2010-2015). WMO TD No 1503. World Meteorological Organization: Geneva. http://www.wcrp-climate.org/documents/WCRP IP_2010_2015.pdf.

WMO. 2009b. Strategic plan for the Implemention of the WMO's World Weather Research Plan (WWRP): 2009-2017. WMO TD No. 1505. World Meteorological Organization: Geneva. http://www.wmo.int/ pages/prog/arep/wwrp/new/documents/final_WWRP_SP_6_Oct.pdf.

Wulfmeyer V, Behrendt A. (eds.) 2007. COPS field report. Available from http//: www.uni-hohenheim.de/cops.

Wulfmeyer V, Walther C. 2001a. Future performance of ground-based and airborne water vapor differential absorption lidar. I: Overview and theory. Appl. Opt. 40: 5304-5320.

Wulfmeyer V, Walther C. 2001b. Future performance of ground-based and airborne water vapor differential absorption lidar. II: Simulations of the precision of a near-infrared, high-power system. Appl. Opt. 40: $5321-5336$.

Wulfmeyer V, Behrendt A, Kottmeier C, Corsmeier U (eds.). 2005. COPS science overview document. Available from http//: www.unihohenheim.de/cops.

Wulfmeyer V, Bauer H-S, Grzeschik M, Behrendt A, Vandenberghe F, Browell EV, Ismail S, Ferrare R. 2006. Four-dimensional variational assimilation of water-vapor differential absorption lidar data: The first case study within IHOP_2002. Mon. Weather Rev. 134: 209-230.

Wulfmeyer V, Behrendt A, Bauer H-S, Kottmeier C, Corsmeier U, Blyth AM, Craig G, Schumann U, Hagen M, Crewell S, Di Girolamo P, Flamant C, Miller M, Montani A, Mobbs S, Richard E, Rotach MW, Arpagaus M, Russchenberg H, Schlüssel P, König M, Gärtner V, Steinacker R, Dorninger M, Turner DD, Weckwerth TM, Hense A, Simmer C. 2008. The Convective and Orographically induced Precipitation Study: A research and development project of the World Weather Research Program for improving quantitative precipitation forecasting in low-mountain regions. Bull. Am. Meteorol. Soc. 89: 1477-1486, DOI:10.1175/2008BAMS2367.1.

Yan X, Ducrocq V, Jaubert G, Brousseau P, Poli P, Champollion C, Flamant C, Boniface K. 2009. The benefit of GPS zenith delay assimilation to high-resolution quantitative precipitation forecasts: A case-study from COPS IOP 9. Q. J. R. Meteorol. Soc. 135: 1788-1800.

Zimmer M, Wernli H. 2008. 'COPS Atlas - The meteorological situation from 1 June to 31 August 2007’. Internal Report No. 1. Institut für Physik der Atmosphäre: University of Mainz, Germany.

Zus F, Grzeschik M, Bauer H-S, Wulfmeyer V. 2008. Design and optimization of the IPM GPS slant path 4DVAR system. Meteorol. $Z$. 17: $867-885$ 